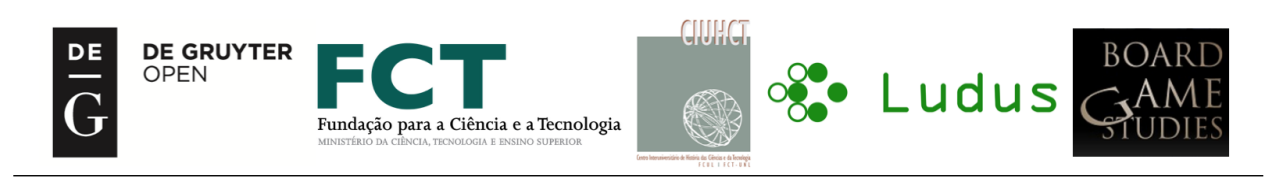

\title{
LE SYMBOLISME DES JEUX CHEZ FILIPPO PICINELLI
}

\author{
Jean-Marie Lhôte
}

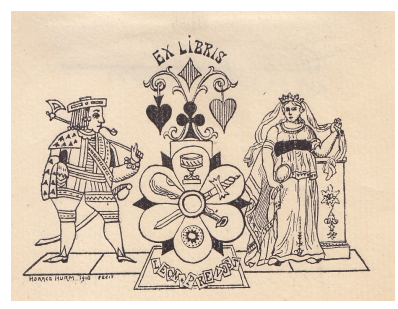

La nouvelle petite aventure $\mathrm{E}^{1}$ commence avec la consultation et l'analyse d'une importante collection d'ex-libris comportant trois mille vignettes environ, du XVIIe siècle à nos jours. Or il s'y trouve une seule image évoquant un jeu : l'ex-libris de Léon Prévost, dessiné par Horace Hurm en 1910, où figurent les enseignes des cartes à jouer et des tarots. Quelques autres montrent des fragments d'échiquier mais sans significations intéressantes. Il est naturel que cette rareté soit aussi marquée dans les emblèmes en général où l'on voit dessinés des animaux, des graphismes ou autres figures symboliques, montrant des personnes, des cités ou des idées et dont les blasons aristocratiques représentent les exemples bien connus. Allons y voir de plus près.

Dans le traité devenu classique de Cesare Ripa, Iconologie ou la science des Emblèmes, paru en 1698 et reprenant l'essentiel des publications antérieures, aucune image sur les quelques cinq cent vignettes commentées, est directement relative au jeu 2 Pour se faire une idée précise de la situation, il convient donc de consulter les livres d'emblèmes eux-mêmes.

Un guide est indispensable. Nous le trouvons avec l'ouvrage de Jean-

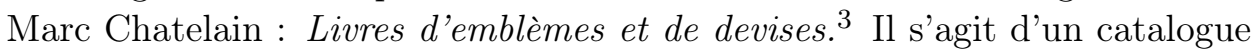

\footnotetext{
${ }^{1}$ Elle rejoint les deux récits publiés il y a cinquante ans dans la revue Bizarre : Degas (1962) ; Shakespeare et les tarots (1967).

${ }^{2}$ Iconologie ou la science des Emblèmes, devises, etc. Qui apprend à les expliquer, dessiner et inventer. Ouvrage très utile aux Orateurs, Poètes, Peintres, Sculpteurs, Graveurs, $\&$ généralement à toutes sortes de Curieux-Des Beaux-arts et des Sciences. Enrichie et augmentée d'un grand nombre de Figues avec des moralités, tirées la plupart de Cesar Ripa par J.B. [Jean Baudoin] de l'Académie Française, Amsterdam 1698.

${ }^{3}$ Jean-Marc Chatelin, Livres d'emblèmes et de Devises, une anthologie (1531-1735), préface de Henri-Jean Martin, Klincksieck, 1993.
} 
commenté des livres publiés sur ce thème en Europe depuis le $\mathrm{XVI}^{\mathrm{e}}$ siècle. Les traités y sont décrits par ordre chronologique accompagnés d'une notice et d'une illustration à titre d'exemple. Publié il y a vingt-cinq ans, en conclusion de recherches couvrant des années, on imagine l'inlassable patience de l'auteur, consultant les éditions originales dispersées dans des bibliothèques. Directeur de la réserve des livres rares à la Bibliothèque nationale, l'auteur possède évidemment toutes les facilités pour ce travail mais l'enquête est considérable. Aujourd'hui, deux semaines suffisent pour prendre connaissance de tous les volumes cités, qui se trouvent accessibles sur le site Gallica ou ailleurs! Ne boudons pas cette facilité.

Effectivement, les représentations de jeux sont très rares dans les emblèmes. Plus de trente volumes énumérés dans ce catalogue sont visités à la recherche d'illustrations représentant des divertissements, des jeux ou des instruments de jeux. Sur les centaines de pages survolées, une vingtaine seulement montrent des images de jeux : dés, balles, échiquiers. . auxquels il faut ajouter des images liées aux beaux-arts : peinture et musique. Il est vrai que l'emblème relève par définition d'un univers sérieux et quasi sacralisé ; le jeu n'y a donc pas sa place.

D'Alciati à Van Haecht, en passant par Bargagli, Camerius, Fabrizi, La Perriere ou Reusner - voici un premier état de cette promenade :

Balle, lancée à la main (Rollenhagen)

Balle, jeu de paume (La Perrière [2], Sambucus)

Course de teste et de bague (Perrault)

Danse (Fabrizi)

Dés, instrument (Bargagli, Pétrasanta, Sambiucus)

Dés, joueurs (Alciat, Boissard, Corrozet, La Perrière, Reusner)

Échecs, instrument (Ferro)

Échecs joueurs (Corrozet, La Perrière [2])

Labyrinthe (La Perrière, Reusner)

Masque de théâtre (La Perrière)

Musique, instrument (Alciat, Ferro [3], Imago, Paradin, Pietrasanta [2])

Musique, joueurs (Horosco, Montanin, Reusner [2], Sambucus)

Peinture, peintre (Bocchi, Cousteau, Horosco, La Perrière.)

Prestidigitation (Sambucus)

Sorts (Bochii, Sambucus)

Tir jeu Arc (Fabrizi, Corrozet, La Pérrière, Piedrassanta)

Tir chasse (Corrozet)

Toupie (Bargagli ; Ferro)

Trictrac (Boissard)

Board Game Studies Journal 11, pp. 1-52 DOI 10.1515/bgs-2017-0001 
En se limitant aux seuls jeux dits de société, le butin est faible : balle, dés, échecs.

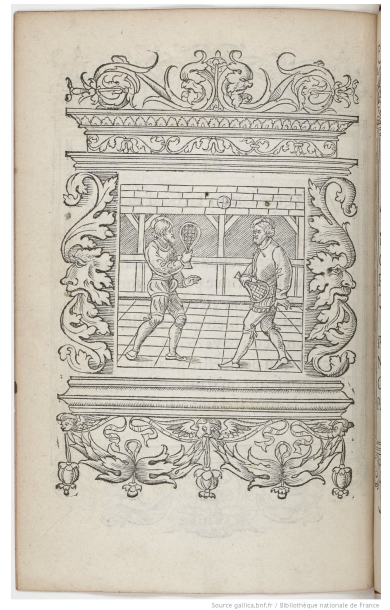

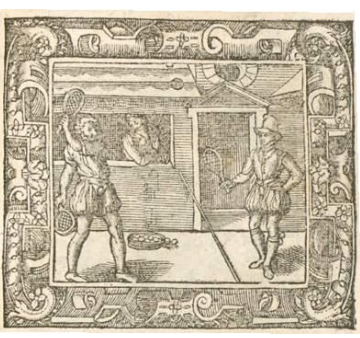

Sambucus, 1566

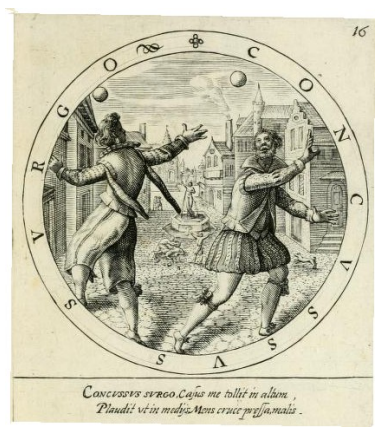

Rollenhagen 1611

La Perriere, 1539

Voici le jeu de paume et de balle. Les livres de La Perrière et de Sambucus sont conçus sur le même modèle, avec une illustration accompagnée d'un court texte. On n'y trouve pas une devise mais un commentaire en vers : sorte de fable dont ressort une morale. L'ouvrage de Guillaume de La Perrière, Le théâtre des bons engins, auquel sont contenu cent emblèmes moraux propose deux fois le jeu de paume. Voici le texte correspondant à l'image ci-dessus - en français moderne : « Si tu te mets à jouer à la paulme, / En te voulant pour passetemps ébattre; / Ne pense pas que ton compagnon chaume, / Car de sa part l'esteuf voudra rabattre. / Penser aussi doit tout homme folâtre ; / Que si par jeu quelques brocard prononce, / Par jeu reçoit la semblable réponse, / Ne pour cela doit fort travailler : / Car en bon poids on vend once pour once, / Pire jeu n'est que moquer ou railler »

Joannes Sambucus présente ses emblèmes moraux de la même manière : un court poème latin accompagnant l'image. Avec Gabriel Rollenhagen, en revanche, nous sommes bien dans le registre de l'emblème proprement dit où les personnages sont des entités illustrant une devise. On remarque ici que les lanceurs de balles en utilisent deux, ce qui n'est pas banal et renforce la performance. Un distique donne l'esprit de l'emblème : «Quand les hommes veulent nous supprimer; Ils nous élèvent plus haut. » La devise proprement dite entoure l'image en forme de médaille. Elle est une réduction de la phrase : Concussus surgo: Quand on me frappe je bondis.

Le jeu d'échecs est présent deux fois chez La Perrière avec, pour cette 


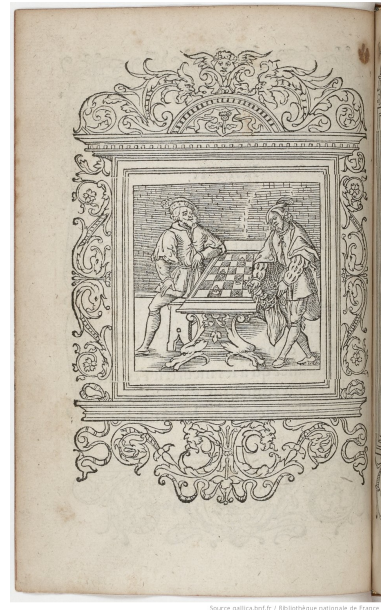

La Perriere, 1539

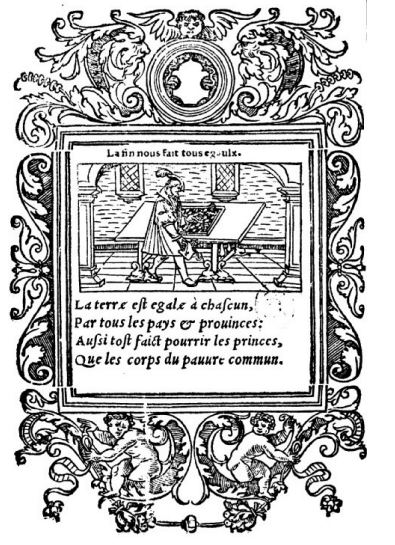

Corrozet, 1540

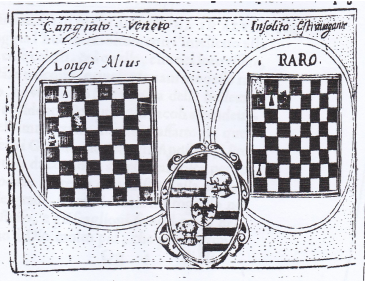

Ferro, 1623

scène, le texte suivant - en remarquant sur l'image le dessin d'un sac où ranger les pièces : «Le Roi d'échecs, pendant que le jeu dure, / Sur les sujets a grande préférence, / Si on le matte, il convient qu'il endure / Que l'on le mette au sac sans différence. / Ceci nous fait notable démontrance, / Qu'après le jeu de vie transitoire, / quand mort nous a mis en son répertoire, / Les rois ne sont plus grands que les vassaux / Car dans le sac (comme à tous est notoire) / Rois et pions en honneur sont égaux. » Même principe chez Gilles Corrozet qui limite son commentaire à un quatrain intégré dans l'encadrement : «La terre est égale à chacun, / Par tous les pays et provinces, / Aussi tôt fait pourrir les princes, / Que les corps du pauvre commun.»

L'abstraction règne chez Giovanni Ferro dans son Teatro d'imprese 4 où les thèmes ornés d'illustrations s'enchainent par ordre alphabétique en formant un recueil d'emblèmes de grande ampleur. Après avoir évoqué sommairement le jeu d'échecs, la figure représente deux positions de pièces en fin de partie avec un échec et mat en deux coups - dont celui de droite "très rare".

Dans cette petite cueillette, les dés sont le plus représentés ; mais cela ne dépasse guère la dizaine, principalement avec des scènes de joueurs...

Sous le titre Infortunes toujours prochaines, Alciat présente trois jeunes femmes jouant aux dés, illustrant le texte suivant : «Trois fillettes jouant aux sorts / Laquelle première mourra / La perte dessus l'une, sort / Qui de

\footnotetext{
${ }^{4}$ Le mot imprese, à cette époque, est utilisé comme synonyme d'adage, de devise. . Les livres d'emblèmes sont des «imprese ».
} 


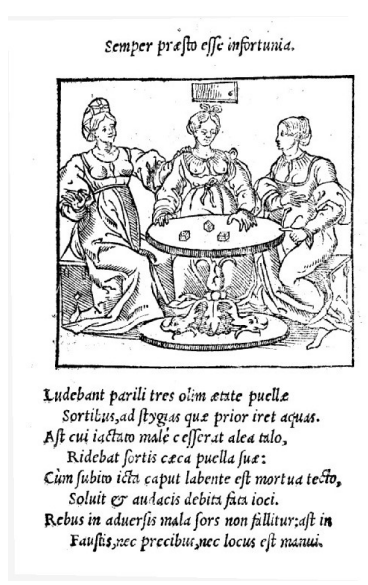

Alciat, 1531

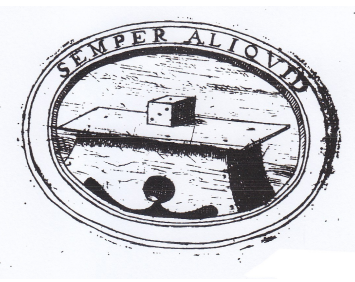

Bargagli, 1594

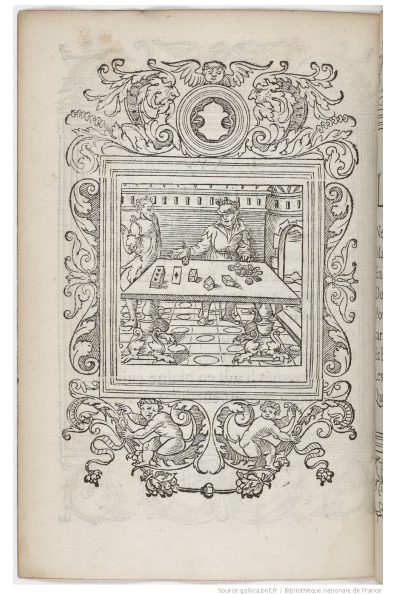

La Perriere, 1539

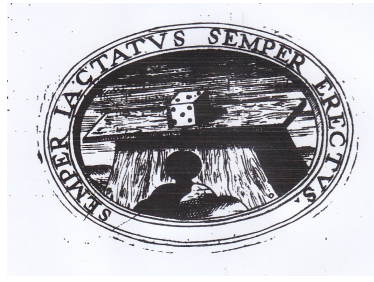

Bargagli, 1594

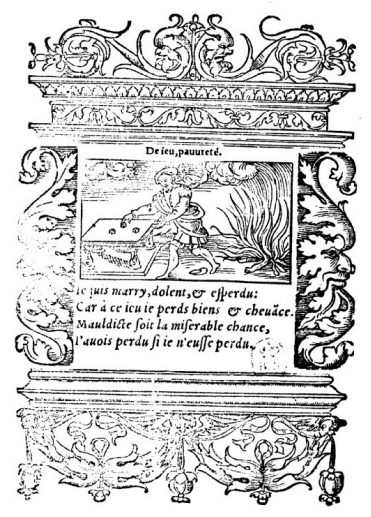

Corrozet, 1540

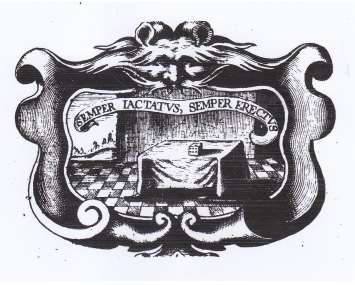

Pietrasanta, 1634

moquerie de ce au cour a / Mais le malheur lui demeura / Car d'une tuile du toit chut / Qui du coup sa vie dévora / et selon son sort fut mescheut [malheur].»\$5

La Perrière évoque le jeu en général en montrant sur la table à la fois dés et cartes, où le démon veille : "L'Homme trop sot en tous jeux se hasarde, / Ne pense au mal qui en pourrait venir : / Main libérale au jeu qui n'y prend garde, / En pauvreté fait l'homme devenir : / Donc là faut lier et retenir, / Pour conserver le bien en bons usages : / Car le jeu met l'homme en fâcheux naufrages / et bien souvent en mortel désespoir/ Les grands malheurs et dangereux passages / Qui en viennent nous servent de miroir. »

Même tonalité chez Corrozet, dans son quatrain : « Je suis marri, dolent et éperdu /Car à ce jeu, je perds bien et chevance [tête] / Maudite soit la misérable chance / L'avais perdu si je n'eusse perdu. »

\footnotetext{
${ }^{5}$ Livret des emblèmes de maistre André Alciat mis en rime française $\&$ présenté à Monseigneur l'Admiral de France, Paris, Chrétien Wechel, 1536.
} 

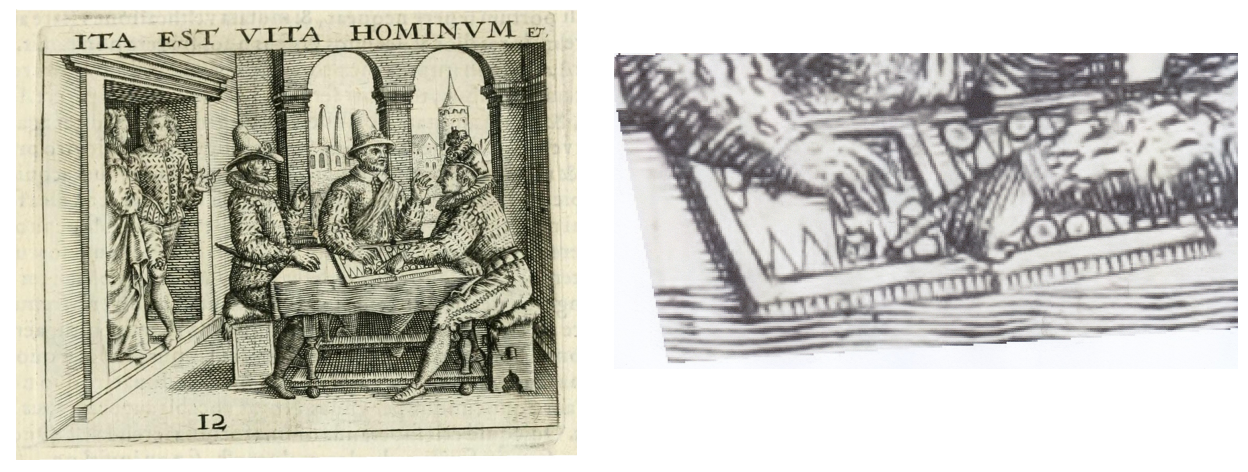

La gravure de Jean-Jacques Boissard comporte divers éléments en plus des joueurs eux-mêmes ; la scène se passe dans un palais avec vue sur un paysage tandis qu'un couple de jeunes gens entre dans la pièce. Mais surtout, ce jeu ne se pratique pas sur une table nue, comme les précédents exemples, mais sur un tablier de trictrac, très clairement dessiné. Autre caractère important, qui n'a pas encore été vu jusqu'ici d'une façon aussi nette, la présence d'une devise surmontant l'image :

ita est vita hominum : «Ainsi est la vie humaine. »

Le texte de complément est :

Iudice, nempe Deo sortis sic alia, nostra

Talorum ut lusu, tessera missa, cadit.

Ut numerorum ergo, vitae sic quosque tueri

Corrigere, qua datur arte, decet.

Ce quatrain a donné lieu à une exégèse savante proposée par un forum anglais en février 2015. Son accès s'obtient directement en écrivant le premier vers sur le clavier google : «Iudice, nempe Deo sortis sic alia, nostra ». Deux membres de cette association latiniste, baptisés Rocit et Imber Ranae, échangent leurs interprétations et sont d'accord sur la formulation suivante :

«Conformément au jugement de Dieu, le danger du destin certainement nous tombera, comme le dé tombe quand on le lance dans un jeu de hasard. Comme avec les nombres, donc. Ainsi également dans la vie, convient-il à chaque homme, avec les compétences accordées, de maintenir ou corriger ses accidents. »

Ceci correspond à la définition des jeux de hasard raisonné dans lesquels l'intelligence du joueur doit trouver la meilleure utilisation possible des données fournies par le sort, dont les jeux de cartes fournissent les meilleurs exemples. Le détail de l'illustration montre bien ici l'attention portée par les joueurs quand l'un deux pointe son index vers le dé. Illustration datée 
1596, d'autant plus intéressante que le premier ouvrage imprimé sur le jeu du trictrac, parait en 1634 - serait-ce la plus ancienne représentation de ce jeu?

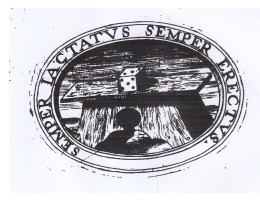

Avec Scipione Bargagli, la devise se fait d'autant plus présente que les joueurs ont disparu, laissant le dé seul, sacralisé pour ainsi dire. Le voici tel qu'en lui-même, posé sur une sorte d'autel.

Lorsque Silvestro Pietrasanta reprend le même thème avec un dé unique, il est placé dans un décor intérieur, sur une table recouverte d'une étoffe, pas tout à fait au centre et près du bord... comme s'il allait tomber ? Du moins la question se pose et il semble que le texte d'accompagnement lui fasse écho, reprenant un thème classique où l'homme sage risque la ruine comme on jette un dé entre le pouvoir de la fortune ou la chute.

L'essentiel ici réside dans la devise, identique chez les deux auteurs. Bargagli comme Pietrasanta inscrivent au fronton de leur image, la phrase : Semper Jactatus, Semper erectus, la devise du dé à jouer luimême : Toujours balloté; Toujours en éveil.
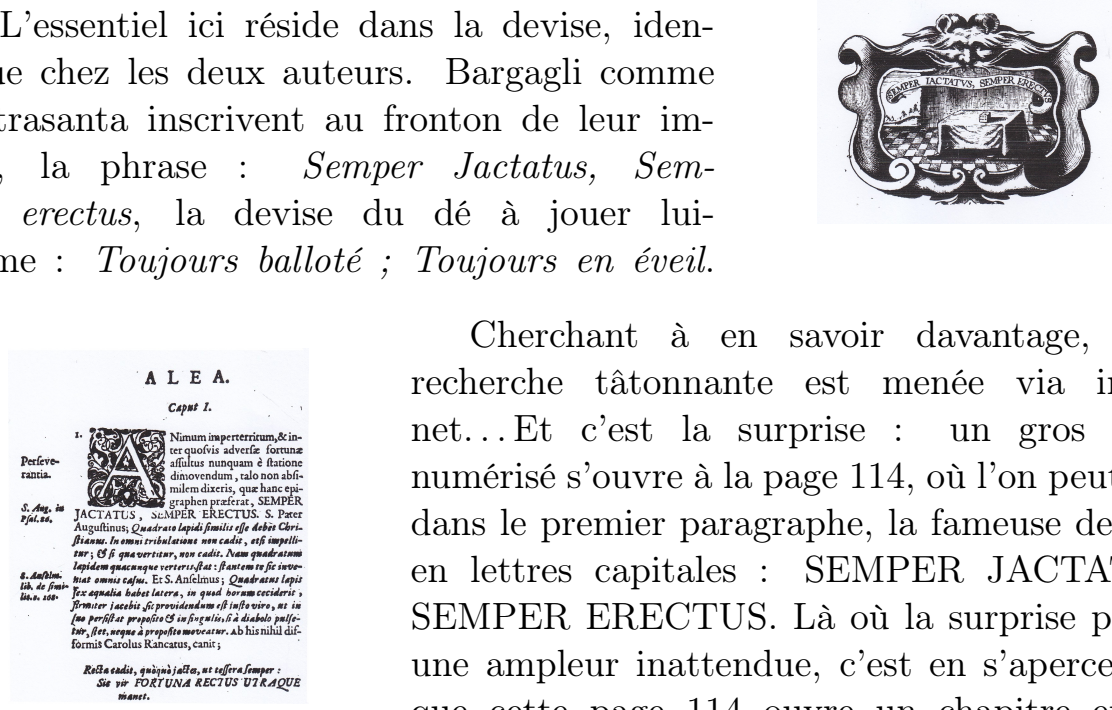

Cherchant à en savoir davantage, une recherche tâtonnante est menée via internet...Et c'est la surprise : un gros livre numérisé s'ouvre à la page 114, où l'on peut lire dans le premier paragraphe, la fameuse devise, en lettres capitales : SEMPER JACTATUS SEMPER ERECTUS. Là où la surprise prend une ampleur inattendue, c'est en s'apercevant que cette page 114 ouvre un chapitre entier consacré... aux jeux! Des pages inconnues à l'enquêteur et sans doute à bien d'autres. Le nom de l'auteur n'apparait pas dans l'index, pourtant bien fourni, du livre de Jean-Marc Chatelain.

L'ouvrage est Mundus symbolicus, de Filippo Picinelli, un théologien italien né en 1604, mort en 1678. Ce traité considérable concernant les emblèmes "universels" a connu plusieurs éditions, la première en italien, datée 1653, suivie de plusieurs autres et des éditions latine, après la mort de Picinelli. 


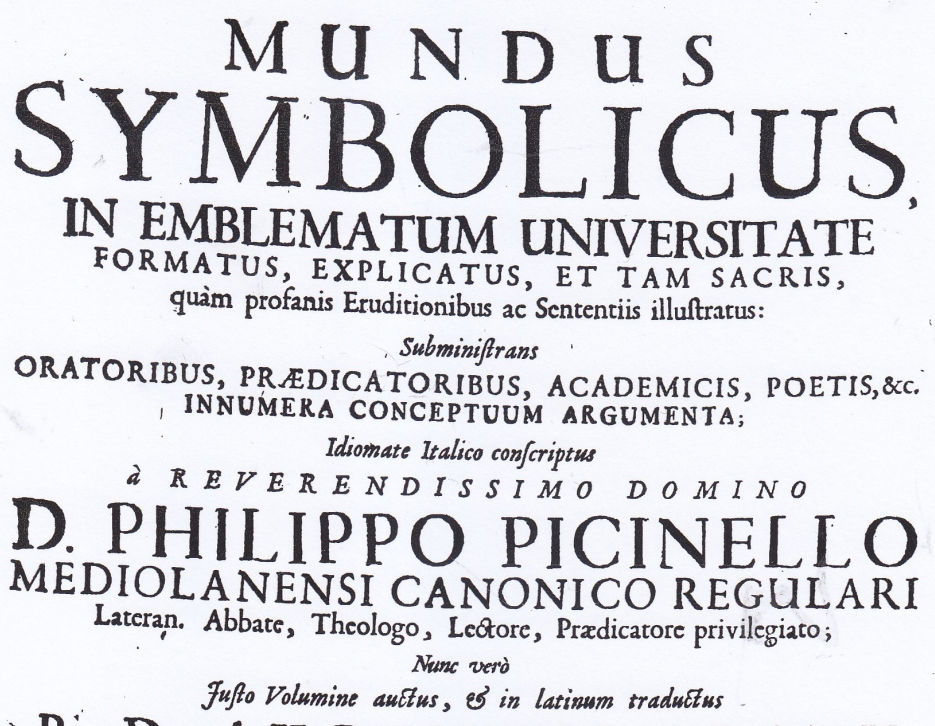

i R D. AUGUSTINO ER A TH, IMPERIALIS COLLEGII AD B. V. IN WETTENHAUSEN, Ordinis S. Auguftini Canonico Regulari, SS. Theologix Doutore ac Profeffore, Protonotario Apoftolico ac Sub-Decano, TOMUS SECUNDUS,

Cum quadruplici copiofiftumo Indice, Lemmatum, Applicationum, Rerum, \& S. Scripturx.

Editio Tertia in Germania.

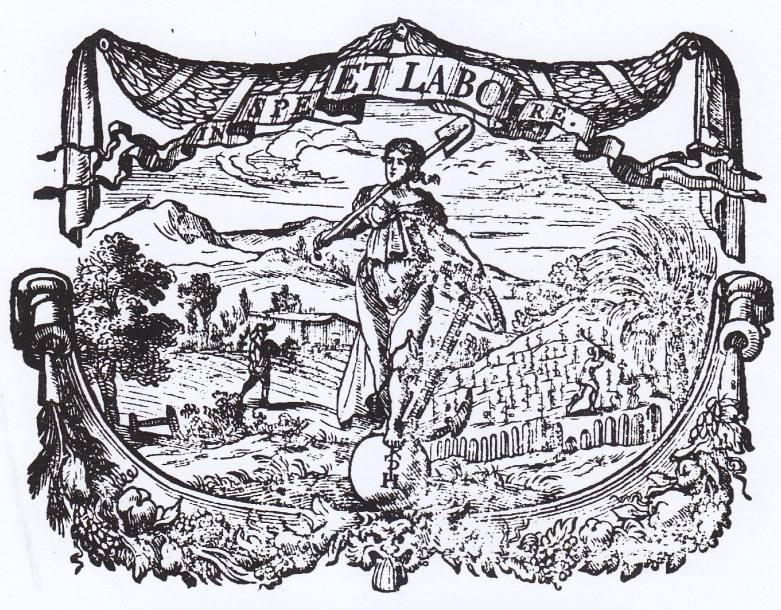

COLONIX AGRIPPINAE,

Sumptibus THOMA \& HENRICI THEODORI Bon COIllm. Anno 1715:

Voici, la page de titre de ce volume 1715, et ensuite la reproduction de cette page 114 . 


\section{aten(ii4) intsis \\ MUNDI SYMBOLICI \\ LIBER DECIMUS OCTAVUS. \\ INSTRUMENTA LUSORIA.}
Alea.
Alveus Latrunculo.
I Pila reticulo
Pyrobolus chartaceus. 6
rum. percuffa.
4 Teffera.
Pila.
2 Pila ventofa, Ligneú Trochus.
3 brachii tegmen.5 Turbo pneumaticus. 9

A L E A.

Caput 1.

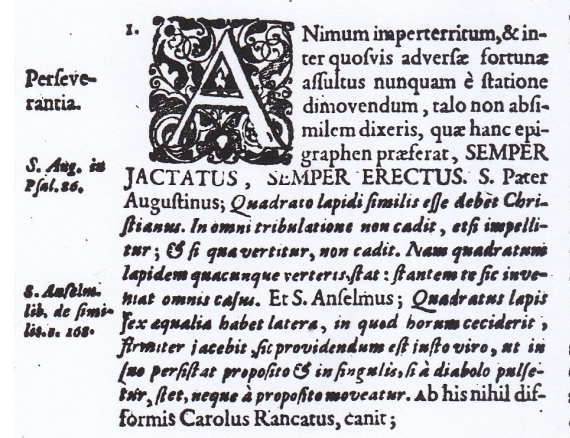

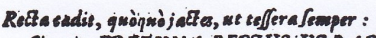

Sif vir FORTUNA RECIUS UTRAQUE

$$
\text { mianset. }
$$

Unde eidem emblemati nonnemo fublcripfir ; QUOQUO VERTAS. Vel, SEMPER IDEM.

seace. Ru. Rurfus hàc icone, ceu ectypo, conftans ac imper-

sot. tetritus hominisanimus repràfentatur. Seneca im mutabilitarem ac magnanimitatemillam inSocraté difertishis verbis deprodicat. Acripire Socratem,

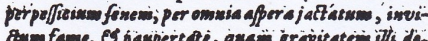
meftisa encra fasiobant, \& laboribus, gwos milis ares

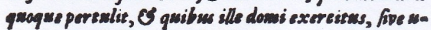
xorew ejws pectios, maribus feraw, livgrad petwlantere, five liberos indosiles, of masri, qudim patri familiores. Objethe oft \&5 roligionum violatio, \& jwveninsis corruptelas gasam imemistere in Deos, in patres, in rempublicam ditius eff. Pof hes riarcor ó benemow. Hec n/ges è animanus Socretis

we ne valtem quidem mowerint. Oc.

Ufure: 2. Fort m centuriis femper ali-

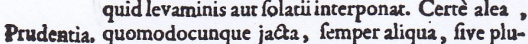

ra, five pauciora, pundea exhibet. Unde lemma : r2, five pauciora, punca exhibet. Undelemma; QUUMODOCUNQUE ALIQUID. Vel, SEM- Kegacis eft ingenium, quí quavis, tam profpe- to, quàm adverfo rempore, quzitus fuos promo-

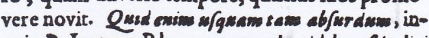
quit, P. Joannes Rho, ex gwo alsymid bonofiti elici P. 10. Rho de

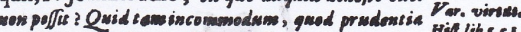
artifice nom molliasur? Nempe S. Gregorio tefte; s. Gres.

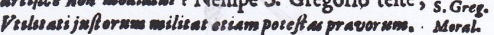

3. Bargalius Symboli loco aliquopt aleas fupra abacum tiguravit, qux, cùm infelicillima puncta abacum nguravit, qux, cum infelicilima puncta è jactu fuo oftenderent, epigraphen tulêre; COR- Prudencia dentiam ac indultriam in forris inaligna defectum dentiam ac indultriam in fortis inaligna defectum Proprius fubftinendam effe, \& quemvis proprix felicitäris Proprit

fux authorem exiftere debere. Socratis dictum e- valor. rat; Alea ludo fimilis off virs : S qusdquid evenis, Socras apowd

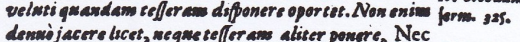
aliter dicebat Plato, quòd in adverfantis fortunx Plase de cafich remed. loro. caficopis CEDIT, Gu ranguam in CEDIT, quomodocngme ratio MELIVS rem babe. re dicar, megotia DISPONERE. Et Seneca; Optimus Senee. de

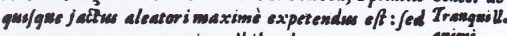

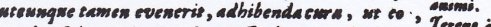

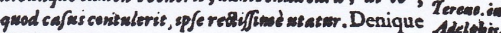
Terentius;

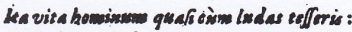
Si illwd, gwod of maximos spew, jacts mon eadis. Illad guod cecidus forre, id arte int corrigas neceffo eft.

Achilles Bocchius Palla Zem figuravit, qua Forru- Acbillae nam jarijam fubmergendam, è tempeftuofo mari Becchios

extrahens, hunc titulum prefixum habuit; Fortune Inblisto

forci fublevanda indxftria. Ita nimirum perniciem, b inimica forte ctearam, tivacinofto pararioporter. T. Quineus Capirolinus, Conful Romanus, cùm unum exercitûs fui cornu è ftatione fugam capeffere cerneret, mox promptiffimo tratagemate altùn exclamavit, hoftes $a b$ altero cornu proftratos effic : ficque, fugitivis ad priftina Iigna convocatis, defideratam obtinuit victoriam. Cnejus Mapiitius, eum perfpeetum-haberer, finiftrú Romanorum cornu ob Fabium, Collegam fuum vulnerarum, \& confulem occifum, jamjam abjecto animo è fur flutem meditari, quantocius pruinisudenti magnanimitate cum aliquot Equitum turmis ugitivos pravertit, \& concitatâ voce clamavit, Ė Collogaw vivere, of fo doxtro cornt viciffo. Nec fefellit eventus; eo enim aftu adver[antis fortunx defeCum correxit, \& è militum fuorum animis, jamjam fuperatis, victoriam extorfit ; uti inter cxtera til. Promo: 
Deux-cent pages environ terminent le livre, uniquement consacrées à quatre Index.

1) Index des thèmes où l'ensemble des chapitres (constituant les 'Livres") se suivent par ordre alphabétique et l'on trouve dans Alea, « Semper jactatus ; Semper erictus $»$.

2) Index des citations, classées par rubriques : «Semper jactatus ; Semper erictus » se trouve dans la rubrique Genérositas.

3) Index des noms propres et des têtes de chapitre.

4) Index des citations provenant de la Bible, des Évangiles et des Épitres.

C'est énorme! Sur trois colonnes pour les deux premiers index et deux colonnes pour les deux derniers, en caractères minuscules. Cela représente un travail colossal, réalisé à la main, fiche par fiche, et ensuite composé lettre par lettre chez l'imprimeur. D'ailleurs c'est toujours avec une grande admiration que l'on feuillète les ouvrages anciens importants, comme les encyclopédies et ici, ce Mundus symbolicus... Ajoutons qu'il existe des illustrations gravées sur bois, mais en petit nombre et absentes, par exemple, dans le chapitre sur les Instruments des jeux de cette édition.

Observons enfin, sur la page reproduite, l'importance des écrits dans les marges. On y trouve deux types d'informations : les plus communes, en italique, concernent les références des citations, très nombreuses, qui courent ainsi d'un bout à l'autre de l'ouvrage ; mais d'autres mentions, d'un caractère romain, un peu plus grand, existent aussi : c'est le cas sur cette première page pour les mots «Perseverentia », «Usura» et « Prudentia », dans la marge gauche et les mots «Prudentia » et «Proprius valor», dans la marge droite. Ces mots accompagnent les différents paragraphes numérotés ; on en voit trois sur cette première page. Tandis que ce Livre XVIII, Instrumenta lusoria, est constitué de neuf chapitres, énumérés en tête, le texte lui-même est en effet séparé en paragraphes numérotés, courant d'un bout à l'autre du Livre sans interruption. On en compte 90 dans ce Livre XVIII. Il faudrait se demander si ce nombre possède une signification symbolique, car le nombre des paragraphes des différents Livres est très variable de l'un à l'autre. Ces mots qui accompagnent les paragraphes donnent à chacun une tonalité, le plus souvent morale, rappelant que notre Filippo Picinelli est un ecclésiastique de haut vol qui ne fait pas oublier ici son état de Reverendissimo Domino.

Avant de commencer la lecture de ce Livre XVIII, un petit retour en arrière est nécessaire car une seule des deux gravures du livre de Bargagli a été prise en compte, celle portant la fameuse devise. Une autre a été reproduite plus haut, portant cette fois la mention : «Semper aliquid »... Elle se rapporte à un écrit de Pline l'Ancien, Ex Africa semper aliquid novi, suggérant 
qu'il y aurait toujours quelque chose en provenance de l'Afrique. Oui, il y a toujours quelque chose à venir en provenance des dés à jouer, que ceux-ci aient été de simples baguettes marquées dans les premiers temps, ou des osselets plus mystérieux à quatre faces. C'est la marque de l'Alea, du hasard, de la chance, du destin... premier nommé dans ce Livre XVIII où l'on trouve les neuf chapitres suivants :

1) Alea (jeu de dés) ; 2) Alveus Latrunculorum (tablier du jeu des latroncules) ; 3) Pila (balle) ; 4) Pila reticulo percussa (balle frappée avec une raquette) ; 5) Pila ventosa, Ligneu brachii tegmen (balle gonflée jouée avec bras protégé) ; 6) Pyrobolus chartaceus (fusées) ; 7) Tessera (dé à jouer) ; 8) Trochus (cerceau) : 9) Turbo pneumaticus (Tourbillon à vent).

\section{HASARD}

\section{Chapitre I}

$\mathbf{1}^{\mathbf{1 5}} \sqrt{6}$ Esprit impérieux, et hors de sa position parmi les assauts infructueux de la Fortune, le dé à jouer est un peu comme le dit cet épigraphe : TOUJOURS BALOTTÉ, TOUJOURS ÉVEILLÉ. Pour saint Augustin, La place d'un chrétien doit être comme une pierre. Dans toutes ses détresses, il ne tombe pas, même entraîné. En effet, la pierre bien taillée à angle droit, par n'importe quel tour, est posée. Donc, trouvez-vous vous-même debout dans ce cas. Et pour Saint Anselme : Les côtés de la pierre carrée à six faces sont égaux dans la chute. 7 Bravement la disposition est à maintenir fermement, en homme prévoyant celle dans laquelle elle persistera cependant dans tous les cas, même si un diable qui se tient toujours, frappe. En ceux-ci il n'y a rien d'uniforme. Charles Rancatus chante : Toujours le dé tombe droit, même remué : Ainsi pour l'homme LA FORTUNE RÉGULIÈRE RESTE DES DEUX CÔTÉS.

Les latinistes modifieront cette traduction à leur gré ; les améliorations sont les biens venues. Une observation s'impose d'entrée : le symbolisme de Fillipo Picinelli est essentiellement philosophique et religieux. Le mot Persévérance accompagnant dans la marge ce premier paragraphe donne le ton et pour bien se faire comprendre, Picinelli poursuit en citant un passage

\footnotetext{
${ }^{6}$ La numérotation des paragraphes est celle des éditions correspondantes : 53 pour la version italienne1653 et 15 pour la version latine 1715 .

${ }^{7}$ Les références des textes cités dans le texte son toujours très précises; elles ne sont pas reproduites ici pour ne pas alourdir, mais il est facile à chacun de les retrouver en consultant l'ouvrage disponible sur Internet.
} 
d'une longue lettre de Sénèque à son ami Lucilius. Sénèque a le cafard, cherche à s'éloigner de la ville et finalement conseille de prendre modèle sur les Anciens ; il se réfère à Socrate, passage que Picinelli réduit un peu et dont voici l'essentiel : " D'ailleurs, s'il vous faut un exemple, prenez Socrate, vieillard éprouvé par tous les malheurs, poussé sur tous les écueils, et que n'ont vaincu ni la pauvreté, aggravée encore par ses charges domestiques, ni les fatigues des camps qu'il dut subir aussi, ni les tracasseries de famille dont il fut harcelé, soit par une femme aux mœurs intraitables, à la parole hargneuse, soit par d'indociles enfants qui ressemblaient plus à leur mère qu'à leur père. [...] Pour calamité dernière, une condamnation le flétrit des imputations les plus accablantes. On l'accusa d'attenter à la religion et de corrompre les jeunes gens qu'il soulevait, disait-on, contre les dieux, contre leurs parents et la république : puis vinrent les fers et la ciguë. Tout cela, bien loin de troubler son âme, ne troubla même pas son visage. Il mérita jusqu'à la fin l'éloge admirable, l'éloge unique que jamais nul ne le vit plus gai ni plus triste que de coutume: il fut toujours égal dans ces grandes inégalités du sort. $\gg 8$

$\mathbf{2}^{\mathbf{1 5}}$ Quel rôle a donc la Fortune, dans ces centaines de calamités ? se demande Picinelli. Certes le dé jeté de n'importe quelle manière montre cinq points de plus ou de moins. . En conséquence, l'idée vient que, de toutes façons, il y a toujours quelque chose. Ceci doit être pris en considération, à la fois dans un succès ou dans la difficulté. Savoir réussir, se renouveler. . . De toutes façons, c'est absurde, dit le P. John Rho9 Bien que venant d'un auteur n'ayant pas une grande stature, Picinelli semble heureux de l'utiliser pour caractériser cette "Fortune" indéfinissable. Il conclut son paragraphe en se référant à saint Grégoire évaluant le pouvoir juste et la puissance de l'action. Deux mots sont dans la marge de ce paragraphe: Usura (Jouissance de quelque chose) et Prudentia (Sagesse, sagacité, prudence).

$\mathbf{3}^{\mathbf{1 5}}$ L'entrée dans le troisième paragraphe apporte un singulier changement de perspective. Elle provient d'une recherche concernant la citation attribuée à Bargaglius (orthographié par erreur sur cette page 114 "Bargalius"). Cette citation est CORRIGO SI NON CECIDIT. Toutes les formules de ce genre font systématiquement l'objet d'une recherche particulière, en sollicitant l'inépuisable et précieux Google. Ici nous sommes renvoyés vers Picinelli, ce qui n'est pas étonnant... mais sur l'édition en italien de 1669. Pourquoi ne pas y avoir pensé plus tôt? Traduire l'italien en français est

\footnotetext{
${ }^{8}$ Lettre 104, traduction J. Baillard, Hachette 1914

${ }^{9}$ Joannes Rho, De passionne domini 1656 ? Interrogationes apologétiquae 1641 Cité dans le livre Morale pratique des Jésuites.
}

Board Game Studies Journal 11, pp. 1-52 DOI $10.1515 /$ bgs-2017-0001 
plus simple que pour le latin... Seulement il y a une nouvelle surprise : En regardant, on s'aperçoit que les deux éditions ne sont pas exactement semblables.

Dans l'édition italienne, en un seul volume, les jeux sont bien traités au Livre XVIII, comme dans l'édition latine; ce livre comporte sensiblement le même nombre de pages; on compte également neuf chapitres, mais seulement 79 paragraphes dans l'édition italienne, contre 90 dans l'édition latine... Surtout, certains jeux sont remplacés. L'édition italienne présente en particulier les Échecs qui disparaissent dans l'édition latine pour faire place aux latroncules. Autrement dit, il convient ici de procéder à des analyses distinctes.

À la fin des deux parcours, italien et latin, il sera sans doute possible de comprendre pourquoi une telle transformation. Observons sans attendre que les deux éditions italiennes (1653 et 1669) se succèdent pendant la vie de Filippo Picinelli, les éditions latines étant publiées après sa mort (à partir de 1681).

La plupart des éditions de l'ouvrage sont désormais accessibles grâce à la fondation Google et ceci depuis une époque toute récente. L'édition italienne utilisée sera la première, celle de 1653. Picinelli va avoir cinquante ans. Voici sur les pages suivantes l'illustration ouvrant ce volume et la première page du Livre XVIII. Le Monde est présenté par une jeune femme - sur l'édition de 1669, elle sera remplacée par Atlas lui-même, portant le globe terrestre sur ses épaules - mais le changement notable vient du nombre des pages : en $1653: 800$ pages; en $1669: 1.200$ pages !

Il faudra revenir sur les différentes éditions, sur leurs dédicaces, par exemple, quand celle d'origine est adressée à la Vierge Marie elle-même et celle de 1669 au Cardinal Barberini... sur leurs variantes en nombre de pages et contenu. La composition d'ensemble est bien fixée dès l'origine avec vingtcinq Livres ; celui sur les jeux reste le dix-huitième et comporte dans la première édition une illustration qui ne se retrouvera plus, celle de la toupie. L'ouvrage s'ouvre par la table des matières présentant le plan d'ensemble. Une première partie concerne les Corps naturels, depuis les corps célestes et naturels, suivi par l'homme, les animaux, les plantes... Une seconde partie traite des corps artificiels en commençant par les instruments ecclésiastiques, les instruments économiques, l'architecture.

Board Game Studies Journal 11, pp. 1-52 DOI $10.1515 /$ bgs-2017-0001 


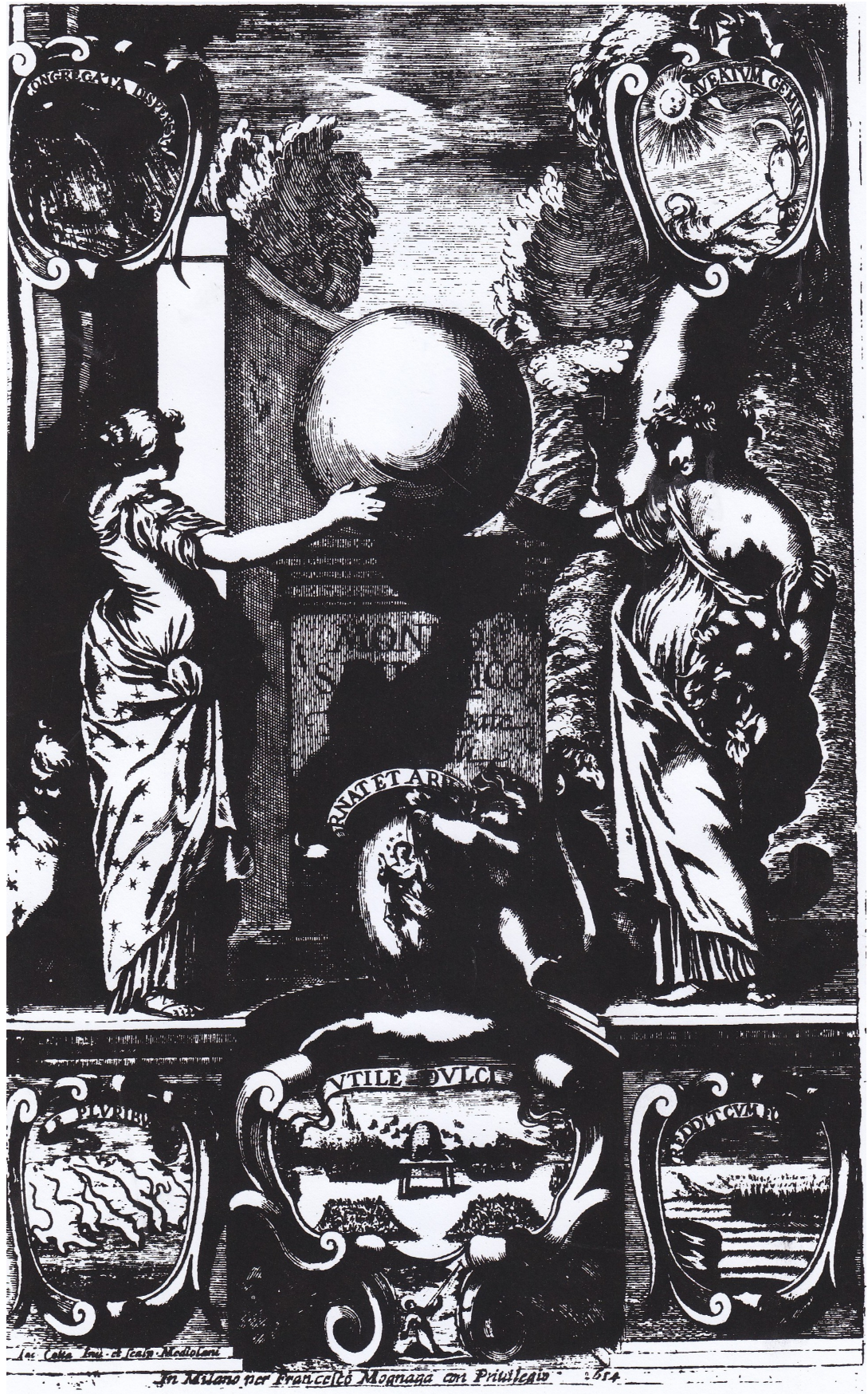

Frontispice de l'édition 1653

Board Game Studies Journal 11, pp. 1-52 DOI $10.1515 /$ bgs-2017-0001 


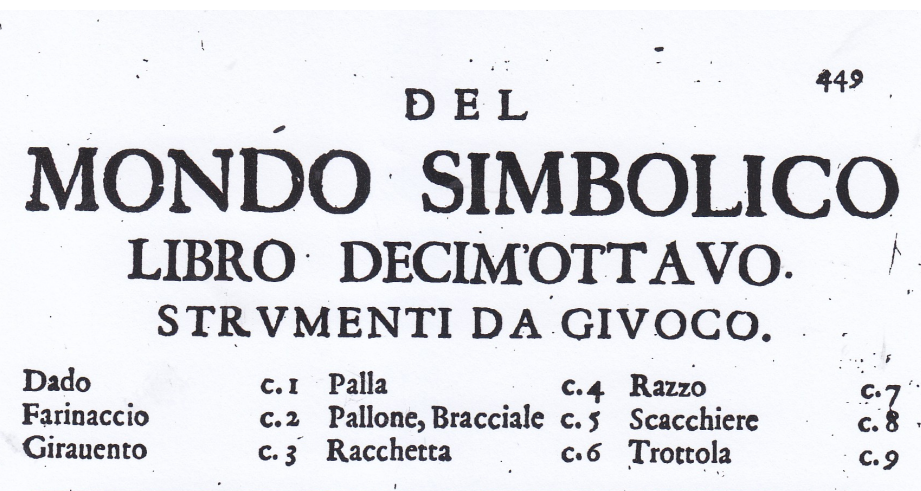

D $\underset{\text { Capo I. }}{\text { A D }}$ O

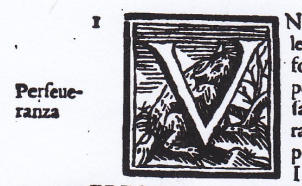

N animo intrepido, chefrà anco; SEMPER ALIQVID, imprefa quadrante le ftrauole della nemica ì perfona fagace, eprudente, che in tutri i tempi, Prudéza fortuna, e fra glimpeti delle profperi, o calamitoin fa qualche acquifto, $e$ daturto perfecutioni- is mantenga co chefegli apprefenta ricaua qualche ptilici. Onid Gionerno ialdo, ed innocente, puó erum pfquamerem abfurdums, diceua il Padre Giouan. Rhe rapprefentarfineldado, ehe ni Rhòde Var. virt. Hift. lib. 5. cap. 1. ex quo aliquid porta il motto; SEMPER bonefii elici non po/jit? Quid tam incomomodnm.

IACTATVS, SEMPER quod prudeneisa artijec non molicatur?

5.Agofi- ERECTVS. Sant'Agottino in PGLl.86. Quadrato 3 Il Bargagli, figurando idadi ful tauoliere', che tapidi fimilis effe debet Cbriftianus. In omnitribua moftrauno cattiui punti,foprafcriffe loro, CORRIwane non cadit, etfi impelitur ; o fi qua verticur, GO SI. NON CECIDIT, inferendo che la doue won cadit. TNam quedratum Lapidens quacunque gli mancaua il fauore della forte: egli fuppliua, diue. Prudeza

5. Anfel e Sant' Anfelmo lib. de fimilitudin. cap. 168. Qua- fefío delle fue buone fortune. Concetto leuato di valore dratus lapis fex aqualia babet latere: in quod borum pelo dal detto di Socrate, riferito da Giouanni Stobea ceciderit firmiter iacebit: fic prouidendum eft Diro ferm. 125 . Alea lado frmilis eft pita: if quidquid Gio: Sto-

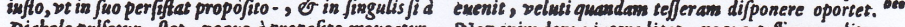

Diabolo puljetur, fiet, neque a propojuso moneatur. Non enim denno iacere litet, neque tefferam aliter al concetto dei quali conformandofi Carto Rancati ponere. E Platone fimilmente lib. 10. de. Republ formò il diftico; citato pur da Stobeo, iui; diceua, che ne gli acciscnti Retia cadie, quoquo iatbes $x$ teffera femper: dell auuerfaria fortuna; Confultare circa ea que Pletome Sic vir, FORTV.NA. RECTVS acciderunt, in primis oportet, \& tanquam in teffer VTR \&que manet. Quindi allo fteffo corpo d' Imprefa altri diede; QVO. que ratio ME LIV'S rem babere dicat, negotic QVO VERTAS, ed altri ; SEMPER IDEM; DISPON ERE. Achille Bucchio, figurando Pallache parimenti inferifcono quefta immutabile conf- de, in atto deftraere dal mar tempeftofo, la Fortuna, tenza. Seneca Epift. 104 con molta facondia và ce- che già ftaua in fommergerfi a ftilfe al fuo emblema lebrando nella perfona di Socrate queftá immutabile s1.il titolo; Fortuna. forti fublewanda induftrien.

somoce animolità fcriuendo; Accipise Socratem perpe $\sqrt{j}$ - Si che la viuacità del noftro ingegno deue riparase Prudéza cium fenem, per annis afpera iachatum, inuidum quei danni, che dalla neraica lciagura ci vengono fame, of paupertate , quem graviovem illi domeffica addoffati. Cosi T. Quiatio Capitolino Confole Roomera faciebant, of laboribus, qwos militares quoq ${ }_{3}$ mano, vedendo cheva cornodel fuo elfercito piegaua pertulit, er quibus ille domi exercitus, fime >xorem alla fuga, con prontifismo giudicio (parfe voceche eius jpectes, woribus ferem, lingua petulantem, frue dall' altro corno erano ftati gli nemici diffipati è fuliberos indociles, o matri, quan pasti smiliores - eati, ed in tal guirs auvalorando i luoi, ottenne 1 obietta est \& religiomam violatio, of iumentusis brig (a) liniltro, dal , mum. Hec rfque eo animum facrat is non mower wnt a fuggire, credendoaltrefi che il Confole foffe uccilo vt ne vultum quidem monerint oc $c$. con prudente animolita , affiftito da alcune trupped 2 Non mai l'auuerfità della fortuna cosi trabalza caualli fi (pinfé loro all' incontro, e gridando ad alra vo miferabile, che non gli lafci qualche refpiro di voce; Et Collegam piuere, of fe dextro cornurvicifles crullio

Acquifto coniolatione, od aiuto, poiche cada il dado come fi in tal guila correffe il mancamento della contraria Froming voglia, che, ò affai, ò poco dimoftra, portando il forte, ed auualorando anco ncl mezzo alle perdite citolo; QVOMODOCVNQVE. ALIQVID; ed gli animi de firoiqqelicemente vinle. Narraciuse di Giu-

Les jeux se trouvant ensuite, l'ensemble se concluant par une série d'instruments mixtes comme la banderole, les lancettes ou le trône. Ajoutons que les toutes dernières pages comportent quelques additions ; celles du livre XVIII 
comptent seulement une dizaine de lignes ; elles seront citées le moment venu.

En fait, des petites différences existent, dès le début, entre les éditions italiennes et latines ; le plus simple dans ce premier temps est de considérer uniquement la première édition, celle de 1653 en recommençant au début, même si les variantes n'apparaissent pas. Différence notable en tout cas : la lisibilité ; L'édition 1653 est d'une qualité très inférieure à celle de 1715.

\section{DÉS}

\section{Chap. I}

$1^{53}$ Modification notable entre les éditions, le chapitre I est dénommé ici "DÉ" Alors qu'il est intitulé "ALEA" en 1715 où ce mot "chance" entraine la pensée dans un univers beaucoup plus étendu que le petit objet cubique marqué de points.

Cela dit, ce premier paragraphe est semblable à celui de l'édition latine vue plus haut.

$\mathbf{2}^{\mathbf{5 3}}$ Quel rôle a donc la Fortune, dans ces centaines de calamités ? se demande Picinelli. Certes le dé jeté de n'importe quelle manière montre cinq points de plus ou de moins... En conséquence, l'idée vient que, de toutes façons, il y a toujours quelque chose. Ceci doit être pris en considération, à la fois dans un succès ou dans la difficulté. Savoir réussir, se renouveler... De toutes façons, c'est absurde, dit le P. John Rho 10 Bien que venant d'un auteur n'ayant pas une grande stature, Picinelli semble heureux de l'utiliser pour caractériser cette "Fortune" indéfinissable. Il conclut son paragraphe en se référant à saint Grégoire évaluant le pouvoir juste et la puissance de l'action. Deux mots sont dans la marge de ce paragraphe: Usura (Jouissance de quelque chose) et Prudentia (Sagesse, sagacité, prudence).

$3^{53}$ Dans ce paragraphe, Picinelli évoque l'attitude que l'homme doit avoir vis-à-vis des aléas de l'existence ce que (à l'exemple de ce qu'on fait quand les dés sont tombés, par rapport à ce qu'en tombant ils ont amené) on prendra, selon l'arrêt de sa raison des dispositions personnelles ; Sénèque est cité en comparant la vie humaine à un jeu de dés où l'art doit corriger les effets de la fortune. Des exemples historiques sont donnés, confirmant l'attitude de prudence à observer face à la vie comme face au jeu. Le mot Prudence est d'ailleurs cité deux fois dans la marge.

\footnotetext{
${ }^{10}$ Joannes Rho, De passionne domini 1656 ? Interrogationes apologétiquae 1641 Cité dans le livre Morale pratique des jésuites.
}

Board Game Studies Journal 11, pp. 1-52 DOI 10.1515/bgs-2017-0001 
$4^{53}$ Les exemples de bonne ou mauvaise fortune se poursuivent : c'est la fameuse observation d'Horace: TANTÔT À MOI TANTÔT À UN AUTRE. . . Accompagnée des vers : "Fortune, que réjouit sa cruelle besogne, / Et qui se divertit sans cesse à nos dépens, / Prends et reprends ses privilèges, / Bonne aujourd'hui pour moi, demain pour toi."11] Virgile affirme l'évidence: "La Fortune bouleverse tout". Toutes les citations sont d'ailleurs soigneusement précisées ; l'auteur est un érudit connaissant les usages. Il convoque même, une fois encore Sénèque... mais ce n'est pas pour sa Tranquilité de l'âme, c'est en se référant à sa tragédie Thyeste, un comble de l'horreur dans le genre puisque deux frères, Atrée et Thyeste, sont en compétition pour un trône et que le vainqueur, Atrée, pousse le sadisme jusqu'à servir comme repas à Thyeste, ses propres enfants ! L'extrait est le suivant: « Il n'est point d'état durable sur la terre : le plaisir et la douleur se succèdent et se remplacent mais la part du plaisir est toujours moindre. Un moment suffit pour mettre un homme du sommet des grandeurs au dernier degré de l'abaissement ». Deux mots dans la marge accompagnent ce paragraphe: Victoire et Fortune.

$5^{53}$ Fini, en effet, l'observation neutre de la Fortune et parfois ses effets heureux. Nous sommes avertis durement dès le début de ce paragraphe par le mot en marge : damnations, au pluriel. Alcibiade Lucarini, est-il écrit, figure un dé dans son gobelet, avec un titre JETER EN TOURNANT en, précisant que c'est un jet dans l'abîme agité, déformé pour cause de tempête, des tempêtes horribles qui s'abattent et investissent quand le feu et le souffre, les orages des vents brulent le cœur. Ils seront agités et versent avec véhémence dans l'incendie éternel des tortures implacables de la damnation, car le Seigneur est juste. Saint Cyprien est sans appel dans sa description évoquant les dents des flammes brulant les corps nus, lamentables, la friture des corps brulés, pitoyable.

Un verset cité renvoie au psaume 92: «Il est bon de rendre grâce à Yahvé /De jouer pour ton nom... » comme pour mieux souligner la damnation de l'enfer où les mots, violence, cuiseurs, torture... sont repris avec une sorte de complaisance ; pour terminer avec Saint Augustin qui parle des douleurs, « douleur de la faim, douleur d'une odeur fétide, douleur de la désolation, douleur de la peur, douleur de la détresse, douleur de l'obscurité, gravité de la persécution, présence du diable, férocité de la bête, ver de la conscience, ardentes larmes, difficultés respiratoires, misère, douleur, sans possibilité de remède, sans paiement, peine de mort éternelle»

$\mathbf{6}^{\mathbf{5 3}}$ Deux mots servent de référence pour ce paragraphe très court : Péché

\footnotetext{
${ }^{11}$ Traduction Jean-Yves Maleuvr.
} 
et Insatiable. "Pour L'as qui occupe la face du dé opposée au six, j'ai donné : SOUS UN BEAUCOUP DE SECRETS, inférant qu'un seul défaut apporte une habitude et peut en cacher beaucoup d'autres.» Aristote dit en effet : " d'une très petite distance qu'on s'écarte du vrai, cette divergence, à mesure qu'on s'éloigne, devient mille fois plus grande. \»12 Une seconde citation d'Aristote exprime le fait qu'il suffit de dire quelques mots à quelqu'un pour que celui-ci se propage auprès de ceux qui en ont le désir, dans un processus infini.

$7^{\mathbf{5 3}}$ Monde trompeur, c'est la leçon essentielle que veut nous laisser Picinelli au terme de ce chapitre consacré au dé et à la chance. Le mot qui viendra par la suite dans les éditions latines, est «fallax », c'est-à-dire fallacieux. Difficile d'être plus clair dans la condamnation générale. Pour indiquer que le monde promet beaucoup, et fait peu, le dé est disposé de telle sorte, que le nombre sous le six conduit à dire : ALORS RETOURNER UN MINIMUM. La référence choisie pour exprimer cette situation se trouve ici avec le roi Salomon construisant le temple de Jérusalem. Il a besoin des meilleurs matériaux et s'adresse au Roi de Tyr, Haram, qui les possède. Le passage du Livre des Rois est cité : «Alors le roi Salomon donna à Hiram vingt villes dans le pays de Galilée. Hiram vint de Tyr pour voir les villes que Salomon lui avait données, et elles ne lui plurent pas ; il dit: "Qu'est-ce que ces villes que tu m'as donné, mon frère" et il les appela terre de Chabul.»

De même, ajoute Picinelli, «La Judée a promis de grandes choses au Verbe Incarné, c'est-à-dire les nobles valeurs et des cadeaux, mais en fait, au lieu de la couronne de joie, elle lui a donné la couronne d'épines ; au lieu d'un beau sceptre d'or, une canne creuse; au lieu de la superbe cape de pourpre, un mauvais tissu déchiré en lambeaux ... Les timbales du bonheur et de la victoire se transformèrent en ailes sanguinolentes de misère et de mort. » Le chapitre se termine par une citation de Saint Bernard qui va dans le même sens de l'inversion des valeurs.

\section{FARINACCIO}

\section{Chap.II}

$8^{\mathbf{5 3}}$ On se demande ce que peut être ce jeu ? Est-ce un lancer de farine pendant un carnaval ?... Il faut le concours d'un Dictionnaire François, Latin, Italien, de 1770 pour découvrir le mot FARINET : «Sorte de dé à jouer qui n'a qu'une de ses faces marquée de points - Farinaccio : sorte de dé. » L'ami

\footnotetext{
${ }^{12}$ Du ciel, traduction Barthélémy Saint-Hilaire.
} 
Thierry Depaulis nous en dit beaucoup plus, en signalant que le farinet apparait dès 1701 dans le dictionnaire de Furetière révisé par Basnage de Bauval : «FARINET - Espece de dé à joüer qui n'a qu'une de ses faces marquée de point, quand on y joüe, on en prend ordinairement six. » Il ajoute : « Malgré cette apparition tardive, je pense que le farinet existait déjà peut- être sous un autre nom. Je retrouve ce jeu, ancêtre probable du "Cloche et Marteau", sous le nom de "Jeu des oublieux", dans l'Essai d'analyse sur les jeux de hazard (seconde édition, 1713). T révous et l'Encyclopédie, sous l'entré Ferme ("jeu de la ferme avec des dés") m'ont l'air de décrire encore le même jeu. Farinet est un clair emprunt à l'italien Farinacci, courant depuis le début du XVe s. » Notre Picinelli reste donc ici dans l'univers de la chance. Cependant sa vindicte antérieure s'estompe. Ce jeu n'est sans doute pas un jeu d'argent aussi redoutable que ceux avec les dés ordinaires. «Monde » placé dans la marge ouvre une autre perspective.

«Le Mondain, qui traite de bonnes œuvres, de jeûne, d'aumône, d'occasions ou ce que vous voulez d'autres offenses à la loi divine; ou ne savent pas quoi que ce soit peuvent se figurer l'as du farinaccio, à propos duquel Lucarini charge : OU RIEN OU TRÈS PEU... De cette manière précisément, opéraient les scribes et les pharisiens qui étaient à juste titre réprouvés. 》 Le texte reprend alors le passage de l'évangile où Matthieu fustige les pharisiens et le thème est développé avec des citations de saint Jérôme ou du pape Grégoire III, en relation avec la règle de ce jeu qu'il faudrait connaître précisément pour comprendre le texte en profondeur. On pourrait penser que le Farinaccio était pratiqué dans un milieu peu recommandable.

$9^{53}$ Le paragraphe suivant est en tout cas beaucoup plus détendu. La marge porte le mot Sarà-faut-il se référer au verbe essere : exister ? À propos de Bargagli, déjà rencontré, qui parle effectivement, du Farinaccio dans son livre, Picinelli écrit : «Formule de Bargagli vis-à-vis du farinaccio : MARQUÉ TOUTES LES FOIS, inférant ainsi que, jeté une centaine de fois, en découvrant quelques points, même à la fin dans une longue patience, que les jets répétés, obtienne enfin que la bonne fortune contredise la mauvaise, pour transformer notre longue attente, tant de fois contestée. " Finalement notre auteur se fait compréhensif devant ce jeu de chance en considérant la vie humaine dans son ensemble et les va et vient de la Fortune. Il semble trouver un certain réconfort en citant ce passage de l'Énéide de Virgile :

«Les jours qui passent et les épreuves changeantes du temps fécond en vicissitudes ont souvent amélioré bien des choses ; la Fortune dans l'alternance de ses visites et de ses fuites s'est jouée

Board Game Studies Journal 11, pp. 1-52 DOI 10.1515/bgs-2017-0001 
de bien des mortels puis les a remis en lieu sûr. :13

\section{MOULINET}

\section{Chap. III}

$\mathbf{1 0}^{\mathbf{5 3}}$ Le mot giravento est absent des dictionnaires Italien-Français récent mais Picinelli nous met immédiatement sur la voie : «Le jouet sert à des enfants pour leur soulagement et plaisir qui déjoue le temps quand les mouvements brusque de l'air l'agitent... »D'ailleurs il répond au titre : PAS DE MANQUE D'AIR. La faiblesse humaine peut se reconnaître dans ce dispositif, même si elle n'est pas adaptée pour bien fonctionner. Il est rappelé que Saint Paul apôtre voit également les pensées vertueuses évoluer comme l'air favorable de la grâce divine. Dans la seconde Épitre aux Corinthiens, saint Paul demande : «Qu'as-tu que tu n'aies reçu? » et Picinelli poursuit en évoquant l'homme honnête et sérieux qui avance vers son règne au loin, pour lequel la grâce divine est comme l'assistance d'une âme. Il cite enfin l'Énéide : «D'abord un souffle vivifie intérieurement, le ciel, la terre, les plaines liquides, le globe lumineux de la lune, et l'astre titanique [le soleil] et l'esprit, répandu par les membres du monde, en meut la masse entière et se mêle avec ce grand corps. $\gg 14$ Ainsi le souffle de l'air qui entoure les mouvements du hochet est-il mis en résonnance avec le grand souffle animant l'univers.

$\mathbf{1 1}^{\mathbf{5 3}}$ Les mots dans les marges offrent le bon éclairage sur le texte. Dans le paragraphe précédent, on trouvait : Nécessité de la Grace-Ministre agissant-Porter de l'intérêt... C'est tout à fait en phase avec l'esprit du texte et des citations ; en même temps le jouet animé par le petit enfant a quasiment disparu ; il ne s'agit pas précisément du symbolisme du petit moulin mais de celui qui nait du mouvement de l'air engendré par son mouvement... Ainsi on parvient aux belles notions divines, couronnées par Virgile. Dans ce second et dernier paragraphe, voici la leçon : Obéissance prête à tout-Instabilité-Faux ami... L'exemple d'Abraham pour l'obéissance ; l'instabilité du cœur mentionné chez saint Grégoire qui parle aussi du mal causé par l'esprit charnel de nos inclinations et du danger des faux amis... Le tout conclut par cette pensée de Silius Italicus, le poète romain du $1^{\text {er }}$ siècle : «La foi de l'homme ne durera pas longtemps quand la fortune chancelle »... Nous sommes tout de même quelque peu éloignés du point de départ, ce

\footnotetext{
${ }^{13}$ Traduction Maurice Rat.

${ }^{14}$ Traduction Maurice Rat
} 
giravento, ce petit moulin qui tourne au vent. Mais comment en vouloir à notre Filippo, un prêtre heureux de faire partager sa foi.

\section{BALLE}

\section{Chap. IV}

$\mathbf{1 2} \mathbf{5 3}^{\mathbf{5 3}}$ L'entrée se fait sans surprise avec la présence de la sphère, caractérisant la balle, symbole de vraie perfection. L'adverbe PARTOUT s'impose. Le croyant s'en remet en tout au Seigneur, comme il est écrit dans L'imitation de Jésus-Christ, l'ouvrage universellement connu de Thomas Kempis : METTEZ-MOI OU VOUS VOULEZ, Traiter avec moi librement en toutes choses. Je suis dans la main FAISANT DEMI-TOUR ET RETOURNÉ ...

$13^{53}$ L'équité est revendiquée ; des références historiques sont données avec un retour au divin proposant un modèle de vertu et prouve une liberté de tous côté, et ronde. Horace illustre ainsi le propos :

Qui est alors libre? Un sage en lui-même impérieux

Lui que ni la pauvreté, ni la mort, ni des liens avec les ennemis,

Méprisant les appétits.

Le Tout-Puissant, qui est en lui-même rond, comme un globe.

L'origine exacte de la citation, pourtant notée Livre 2 Satire 7, n'a pas été retrouvée; il s'agit ici d'une interprétation des vers cités. Notons que les mots en marge de ces deux premiers paragraphes sont Obéissance et Équité.

$14^{53}$ Le caractère sacralisé de la balle se

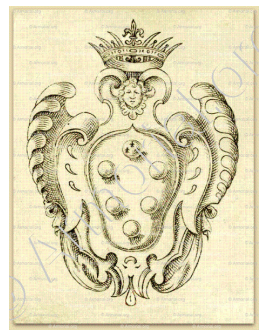
trouve ici sur le blason des Médicis, dont le nombre des onze boules d'origine avait été progressivement réduite à six, celle du haut étant orné de la fleur de lys par la grâce du roi de France Louis XI, en reconnaissance des services rendus. Picinelli s'y réfère à propos de la canonisation de San Carlo [Charles Borromée] en 1610 «sous le symbole d'une balle présente sur le blason des Médicis, avec une inscription NE JAMAIS S'ÉTENDRE, dans laquelle est conforme cette autre devise de Lucarini : FIXE QUOIQUE BALLOTTÉE [...] Vous ne pouvez jamais dire qu'elle est couchée; cette constance est la vertu hérö̈que de ce saint... E Effectivement la biographie de Charles Borromée est tout à fait édifiante. 


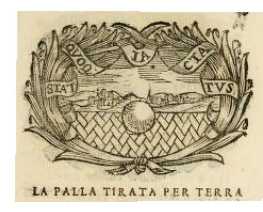

Un des intérêts de ce paragraphe est la référence faite à Lucarini - et ce n'est pas la dernière fois. Alcibiade Lucarini est en effet l'auteur de Imprese dell' Offitioso, publié sous le nom «Accademico intronato » en 1628-1629. Cet auteur a échappé à la sagacité de Jean-Marc Chatelain, et nous sommes enchantés de le découvrir. Son livre est composé sur le mode classique avec une illustration et un petit texte par page. Dans ce volume nous découvrons une allusion aux dés (avec son gobelet), mais surtout pas moins de neuf "imprese" dédiés à la palla, dont celui-ci qui vient d'être cité STAT QUOQUE JACTATUS .

$15^{53}$ Lors de la canonisation de saint Charles, le ballon a été placé sous la devise : UN POINT, pour indiquer que l'on aime la balle parfaitement sphérique, comme enseigné par les philosophes... Le thème est développé avec l'image du saint littéralement soulevé en Dieu. Comme c'est le cas le plus fréquent, Picinelli conclut le paragraphe avec une citation. Celle-ci est empruntée à Zacharie pour marquer cette joie de la canonisation et le salut : «Yahvé, leur Dieu, les sauvera en ce jour-là, comme un troupeau il paîtra son peuple (comme des pierres de diadème étincelantes) sur la terre $\times 15$ Les références indiquées dans le cours du texte sont toujours très précises. Le paragraphe est placé sous le signe de la Contemplation.

$16^{53}$ La balle tombée sur le sol est écrasée ; elle décline ; elle est l'image de l'humilité. Par Bonheur Dieu ne nous traite pas selon nos péchés. Le Psaume 103 nous le dit. De même Saint Bernardin de Sienne et mieux encore, peutêtre, Thomas de Kempis dans L'Imitation de Jésus-Christ : «Dieu protège l'humble et le délivre, il aime l'humble et le console, il s'incline vers l'humble et lui prodigue ses grâces, et après l'abaissement, il l'élève dans la gloire. $\times 16$

$\mathbf{1 7 ^ { 5 3 }}$ De la Constance... La rondeur parfaite de la balle, figurée sur un plan égal, nous dit l'état où l'on se trouve quand on roule. Cela dénote un courage indomptable, et invariable à toutes les révolutions de Fortuna... L'origine de la citation finale est difficile à situer exactement mais il s'agit des qualités reconnues à un général célèbre : «Est-il permis au gouvernement d'une chose par une autre, sur les degrés que vous avez obtenu, avec le plus grand honneur de parvenir au sommet, que vous restiez le même ; cependant, vous n'êtes pas modifié dans la mesure où serait apparue une entrave de l'âme. 》

$\mathbf{1 8 ^ { 5 3 }}$ Ce paragraphe présente une difficulté. Picinelli se réfère à Giovanni

\footnotetext{
${ }^{15}$ Zacharie 9 : 16. Les citations des livres saints sont celles de la Bible de Jérusalem.

${ }^{16}$ Trad. Lamenais .
} 
Ferro en disant : «La balle, du drap mortuaire, présentée, évoque le mouvement...». Or cette image n'a pas été retrouvée dans son Teatro d'imprese ; sans doute se trouve-t-elle ailleurs. Quoi qu'il en soit le paragraphe comporte dans la marge, les deux mots : Travail et Monde. L'activité est au rendez-vous. Une citation du Psaume 15 évoque l'homme qui demeure avec Dieu : «Il regarde avec dédain celui qui est méprisable; Mais il honore ceux qui craignent l'Eternel. »

$19^{53}$ Nouvelle allusion aux armes des Médi-

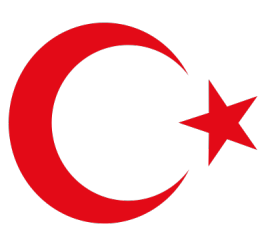
cis, cette fois en relation avec les galères de la Sérénissime Grand-Toscane données en route vers la Turquie, laquelle possède un blason figurant le globe lunaire : ORBE INCOMPLĖTE... Pour bien marquer qu'il ne s'agit pas d'une vraie balle, mais d'une sorte de balle inachevée, Picinelli écrit dans la marge : Péché véniel !

La curiosité de ce paragraphe, tient à la citation finale, emprunté à Alciat, le maître initiateur des emblèmes, puisque la première édition de ses œuvres date de 1531 et connaîtra une longévité remarquable. Ce "péché véniel" est le signe de ceux qui trop facilement quittent le chemin de la vertu. Ceci est illustré dans l'édition 1584, à laquelle se réfère Picinelli, par les quelques vers suivant accompagnant l'illustration jointe :

« Tout comme la petite limace, la remora, qui fausse l'impulsion du vent et des rames, peut empêcher un navire de bouger, ainsi une raison insignifiante tient à l'écart au milieu du parcours, celui qui, par intelligence et capacité, se dirige vers les étoiles. »

Alcibiade Lucarini a fait usage des balles

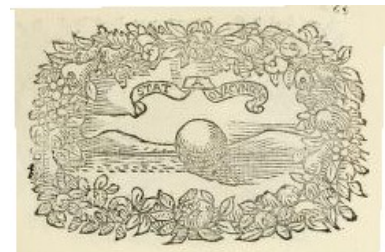
ornant le blason de la Maison Medicis pour exprimer divers concepts liés à l'idée que le sérénissime grand-duc avait beaucoup de pouvoirs, et sur terre et en mer. Il figure ainsi une balle avec la devise : STAT A QUACUNQUE (FIXE EN N'IMPORTE QUEL ENDROIT). Devise applicable à un esprit de bonne volonté qu'entre une bonne ou une triste aventure il ne peut pas être en reste, mais fixe et permanent dans l'une et l'autre situationce qui est affirmé dans la marge avec le mot Constance.

$\mathbf{2 1}^{\mathbf{5 3}}$ Ce paragraphe est placé sous le signe des mots : Mort, Félicité, Caduque... Ce n'est pas gai, le héros servant d'exemple étant le pape Léon XI, décédé après seulement dix-sept jours de pontificat, en 1605. Mais l'occasion est trop belle pour la laisser passer quand il s'agit une fois de plus 
d'évoquer un événement où la balle est présente ; en effet Léon XI n'est autre qu'Alexandre Ottaviano de Médicis, et son blason papal est effectivement celui de sa famille orné de balles.

DU BAS AU SOMMET est la devise mise en exergue avec un vers de Sénèque : Mais une heure courte changera le lot du plus haut et du plus bas. Pour Ausonne: Fortune jamais dans le même état / Toujours en mouvement, avec changements et changements de place / Le meilleur à la fin se trouve être tourné sur lui-même. Un long fragment d'une Élégie d'Ovide conclut la référence à ce pape situé sous le signe de la balle.

$\mathbf{2 2}^{\mathbf{5 3}}$ Équité. Pour illustrer la grande équité induite par la sphère de la balle, Lucarini prend

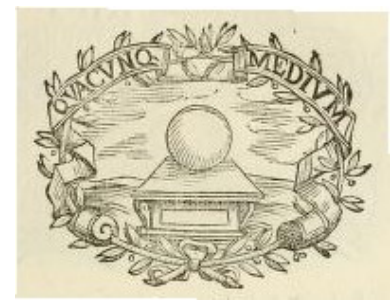
exemple sur Cosimo II et sa grande justice. Encore un Médicis ! Jeune, il eut comme précepteur Galilée, ce qui n'est pas rien...Il en resta l'ami et indépendamment du fait que ses hautes fonctions de Grand-duc de Toscane sont saluées par les historiens comme celles d'un responsable sage et intelligent, il fut admiré pour son sens de la justice, tel que l'exprime la de-

vise de l'emblème de Lucarini : QUACUNQUE MEDIUM - CENTRE PAR N'IMPORTE QUEL ENDROIT. Échapper aux extrêmes est une voie de sagesse. Deux citations d'Horace l'expriment : «La vertu est un moyen terme entre deux vices et à mi-chemin des deux. » ou ailleurs : «Il y a une mesure appropriée dans les choses. Il y a, en fin de compte, certaines limites qui dépassent et au-delà de quoi ce qui est juste ne peut pas exister »Autrement dit : «Tout avec modération $\gg 17$

$23^{53}$ La balle ordinaire... Effectivement

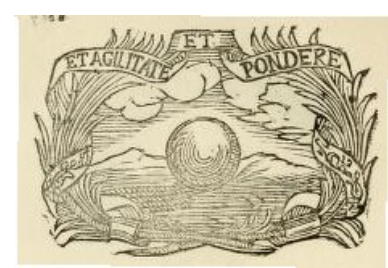
c'est le nom donné par Lucarini à la vignette cicontre, "La palla andante", portant la devise ET AGILITATE ET PONDERE-ET L'AGILITÉ ET LE POIDS. Idée d'une union des contraires pour une personne qui mêle à la maturité du conseil, l'habileté, et la dextérité. Picinelli va chercher l'exemple du personnage dans la Jérusalem délivrée de en précisant bien l'endroit (Cantique 19 verset 11) et il faut vraiment être imprégné de l'œuvre du Tasse pour en comprendre la portée en lisant les deux vers cités : «Le corps de

\footnotetext{
${ }^{17}$ Traduction et interprétation cueillies chez Google, comme beaucoup d'autres non précisées.
}

Board Game Studies Journal 11, pp. 1-52 DOI 10.1515/bgs-2017-0001 
Tancrède agile et lâche / Et aussi vite, et le pied. »...

$\mathbf{2 4}^{\mathbf{5 3}}$ Mort innocente, dit la marge. Dans la mort, j'ignore mon caractère affirme Lucarini

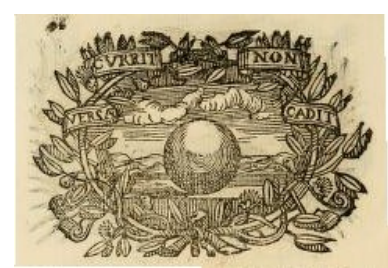
en proposant de nouveau une balle ordinaire : CURRIT NON CADIT-COURRIR NE PAS TOMBER, inférant que tel ou tel a couru pour la carrière d'une humanité mortelle. Vie toujours droite ; il ne tombe pas dans une faute. La vérité se trouve dans la mort d'Abel et Picinelli cite Isaïe : "Mais ceux qui espèrent en Yahvé renouvellent leurs forces, il leur vient des ailes comme aux aigles. Ils courent sans lassitude et marchent sans fatigue. »

$25^{53}$ En montrant cette balle, avec la de-

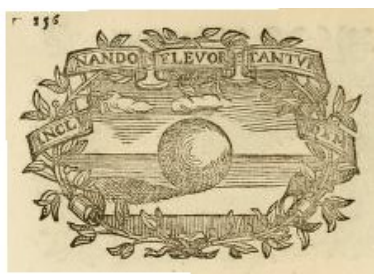
vise : INCLINANDO ELEVOR TANTUNDEM / SOULEVER LA MÊME QUANTITÉ INCLINÉE, Lucarini nous dit qu'elle est l'instrument faible d'une exaltation : Si elle s'abaisse d'un côté, elle se soulève de l'autre. Les mots dans la marge soulignent le propos en répétant Humilité et Exaltation.

$\mathbf{2 6 ^ { 5 3 }}$ Ce chapitre consacré à la balle se termine par un long paragraphe sous l'égide de la Bravoure et de l'Exemple. Brave, héroïque, nous dit Picinelli, est la valeur invincible montrée par la balle de distribution envoyée comme un projectile fracassant chaque mur, tout en restant elle-même, tel que le montre le titre d'un imprese de Lucarini, [non retrouvé] : Aller au-delà, sans rupture, en bon état. Echauffement avec ferveur de la vertu; exaltation du feu de la foi « où tout le monde dans les flammes de la charité, irradiés de lumière...» Saint Bernard évoque la puissance de la conversion; de même saint Augustin, et la conclusion est donnée avec une référence à Ignace de Loyola [mentionné dans la marge] : Homme de feu, quand les flammes célestes l'avait transformé, l'enflammant dans son amour divin.

\section{BALLE AVEC BRACELET}

\section{Chap. V}

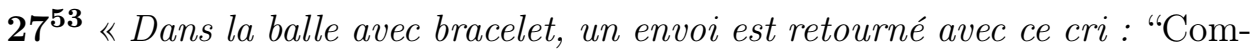
bien ce coup va acquérir". Idée d'un pécheur en sa malice, si bien que Dieu est affecté de diverses manières... » Picinelli ouvre ainsi ce chapitre. Il poursuit 
en citant Jérémie : «Tu les frappes et ils ne sentent rien, tu les consumes et ils ne veulent pas recevoir instruction... » Ce faisant, il s'attaque au sport le plus à l'honneur en Italie!

Sa vogue était intense de son temps ; elle s'est poursuivie jusqu'au vingtième siècle où le football a pris le relais. Le bracelet est une sorte de manche en bois léger et résistant que le joueur enfile et avec lequel il porte ses coups, son adversaire répond dans des conditions données ; la partie se joue en individuel ou par équipe de deux. La condamnation est ici sans appel quand on lit dans la marge : Pécheur défaillant.

$\mathbf{2 8}^{\mathbf{5 3}}$ «Il était de ceux qui frappait la balle avec une grande force - plus il cogne, plus elle s'élève-ou plus brièvement, en la personne de la balle: encore battue pour soulever et ainsi plus élevée. Et il montre que la vertu des coups adverses augmente encore l'élévation des siens... \ Mais le mot couronnant le paragraphe est "Juste". Quelques vers du poète contemporain Girolamo Petri, évoquent l'impiété gagnant la terre quand, au contraire, l'âme non fugace, prend le ciel gratuitement.

À côté du frère violent, le cour de l'autre homme, juste, plus que jamais sollicité avec la proximité de Dieu est conduit à une plus grande perfection et de nouveaux mérites. Et puisque nous sommes dans le domaine sportif, une citation empruntée à Saint Grégoire parle opportunément d'un "Athlète de Dieu".

$29^{53}$ Pour Léon X [Jean de Médicis] à travers la force et la valeur, le gouvernement du Monde est non seulement une puissance vigoureuse, mais également une dextérité à l'image du la balle avec bracelet.

$\mathbf{3 0}^{\mathbf{5 3}}$ Intrépidité est le mot qui situe le paragraphe. Nous ne sommes plus, comme au début, dans le péché, mais Picinelli évoque les qualités du jeu... Un cour intrépide montre que la balle, au milieu des eaux ondoyantes, des vents contraires et des tempêtes menaçantes est bien vivante.

$31^{53}$ Attention, cependant : le ballon gonflé invite à penser élévation et ascension de sorte que ceux, empli d'un saint Esprit, sont soulevés selon une opération divine... mais ceux qui sont promus à de nombreuses richesses et dignités, se gonflent de fierté. Ils font penser, selon Justus Lipsius, à un sac de cuir gonflé, balloté au gré des courants et des vents, bondissant hors de lui-même.

$32^{53}$ Le ballon gonflé rappelle cette pensée de l'Ecclésiaste : «Vanité des vanités, tout est vanité. » Saint Ambroise évoque les applaudissements, les nuits glorieuses de feux d'artifice, tandis qu'à côté, certains, éprouvent des douleurs contraires aux joies, douleurs lourdes dans ses succession d'états. La référence empruntée au Livre de la Sagesse n'est pas heureuse pour ceux qui se pavanent plein d'orgueil : «Le Seigneur les précipitera muet, la tête 
la première »Et pour bien se faire comprendre, Picinelli termine par une référence au second Livre des Maccabées, là où Anthiocus « .. qui tout à l'heure se croyait dans sa jactance surhumaine, commander aux flots de la mer.... Se trouva dépouillé de cet excès d'orgueil et commença à prendre conscience des réalités...»

\section{BRACELET}

$33^{53}$ Ce titre ne désigne pas un nouveau chapitre. Il est celui d'un long paragraphe proposant une méditation à partir de la notion de "bracelet" mais d'un rapport très lointain avec le jeu traité à l'instant. Il est question du "bras de Dieu" et de sa puissance en référence à saint Augustin et à un cantique : "Il a montré la force de son bras".

\section{RAQUETTE}

\section{Chap. VI}

$34^{53}$ La raquette porte les mots : ALLER MODÉRÉMENT LOIN. Cela montre qu'une très légère passion, mais puissante, peut nous aliéner la loi de la vertu ; on lit dans la marge : Péché véniel-DémonObéissance. Autrement dit, la prudence est de mise, ici comme dans bien d'autres jeux. Le voyage en Inde de

\section{RACHET TA Capo VI.}

$34 \mathrm{P}$ Ortò la: racchetra il motto; VI MODICA leggera ,é poffente, à aramoitra molto allonatanare dal di- veciale leggera ,é poffence, à farci molto allontanare. dal di- $v$
ritro della virtü; o pure che il Demonio, benche privo di forze, con quelle poche ad ugni modo grande- Demomente ci sbatte. Non altrimenti la virtù dell? Vbbi- nio dienza, con vn folo commando caccia gli huomini per fino in capo del Mondo, ciò che s'aucerti in San Vbbidie Francelco Xauerio; che deftinaro al viaggio dell' $z a$

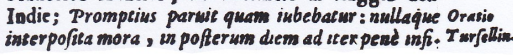
saint François-Xavier est cité pour montrer une destinée exceptionnelle, qui entreprend ce voyage à l'extrémité du monde, par obéissance.

$\mathbf{3 5} 5^{\mathbf{5 3}}$ Grande agitation avec la raquette avec laquelle on aime donner des coups... « Mais pas le perdant; et il ne gagnera jamais dans le jeu celui qui perd son temps. »Une citation du Livre des proverbes exalte le jeu : «M'ébattant sur la surface de la terre et mettant mes délices à fréquenter les enfants des hommes. » Ce n'est pas simple quand «ce qui sauvera en Dieu qui a écrit que sa sagesse infinie est assise. »

Le monde du jeu est similaire à un jeu de balles, transférées de l'un à l'autre et Plaute a écrit : "Les dieux nous font aller et venir comme des balles à jouer. 》 Quant à Boèce, il nous dit à peu près : «Il a introduit 
la Fortune, qui en fait n'est rien que la simple Disposition divine à mourir »Picinelli évoque le jeu se jouant en continu, un roulement de roue sur la pensée faisant tourner les choses à l'envers. Il conclut en se référant à Job, chargé de misère, dont le merveilleux bonheur a augmenté.

\section{FUSÉE, ÉCLAIR, PÉTARD}

\section{Chap VII}

$\mathbf{3 6}^{\mathbf{5 3}}$ Picinelli suggère de faire servir la fusée à l'expression concrète de l'amour. Ainsi, s'élève l'idée de spiritualité et d'autres concepts nobles alors que le cœur s'enflamme - un effet qui a une portée spirituelle pratique, parce-que l'âme s'élève dans une communion avec Dieu. La citation de Saint Augustin va dans le même sens : «Dieu, monta, volant au-dessus, Amour de celui qui est monté. » Folie d'amour est écrit dans la marge.

$37^{53}$ La fusée avec un bâton brulant invite à dire que, pour chacun, le vol soulève la question de la faveur du saint Esprit. Tout est feu. Notre cœur se soulève de terre et monte au ciel. Ainsi pense saint Augustin. Esprit saint est écrit dans la marge.

$38^{53}$ Ce paragraphe évoque les âmes du purgatoire car la fusée élève et suscite une prière : «Seigneur, ne manifeste pas ta colère... » Après la mort charnelle, certains sont destinés à la mort éternelle, les autres pour la vie dans les feux du purgatoire. Alors vient la possibilité d'une rédemption avec l'évocation du prophète Élie qui, après avoir réalisé de nombreux prodiges, s'envole dans le ciel dans un char de feu, se trouve à la vue de Dieu parce que la charité intense vers Dieu, pour lequel il était prêt à mourir, et l'amour de servir ses ennemis pour lequel il a prié ont fait que les cieux se sont ouverts. Jésus a observé. Ce concept relie l'amour de Dieu et l'amour du prochain.

$39^{53}$ Un Monseigneur fait une figure du purgatoire en peignant le folgoretto-l'éblouissement-dévoré par le feu avec le cartel : Je peux monter. Une citation du "petit" prophète Habaquq donne l'éclairage : « J'ai entendu! Mon sein frémit. À ces bruits mes lèvres tremblent la carie pénètre mes os, sous moi chancellent mes pas... \Triste purgatoire, une fois encore écrit dans la marge.

$40^{53}$ Tourments à venir... Pour l'idée d'une âme que Dieu souleva, tout vient tourmenter et troubler. L'abbé Sélarolo figure le razzo avec le feu tournant sur lui-même, et les mots : «Me donner des ailes ». Saint Pierre Damiani, réformateur de l'Église au XI ${ }^{\circ}$ siècle, parlant d'affliction confirme : « J'aime les défis de l'avenir afin de faciliter la sortie de l'honneur ; torture de la présente roue...»

Board Game Studies Journal 11, pp. 1-52 DOI $10.1515 /$ bgs-2017-0001 
$41^{53}$ Tourments soulagés... Suite de la méditation ou le feu du razzo devient feu de l'esprit, avec pour terminer une référence à saint Paul animé d'un feu intérieur spirituel.

$\mathbf{4 2}^{\mathbf{5 3}}$ Dans la mort ... Une trombe de feu que jette l'air des fusées, subitement se désintègre en de minuscules étincelles. Ce passage propose une méditation sur la mort illustrée de plusieurs citations, dont celle empruntée à un sonnet de Pétrarque que voici dans une traduction française de l'époque de Picinelli (1669) : «Ah! vie, qui parait si pleine de charmes. Faut-il qu'un malheureux moment détruise ce qu'une longue suite d'années a eu tant de peine à acquérir. »

$43^{53}$ Obéissance... «Une âme véritablement éveillée au service des vertus ne veut travailler en rien sur sa propre volonté mais dépend entièrement de la volonté de ses supérieurs et des devoirs d'obéissance... \ Ceci est ce que le père Famiano Strada a figuré dans une fusée attachée à un fil. Le paragraphe donne des exemples d'obéissance.

$44^{53}$ Glorieux principes... Dans ce paragraphe, Picinelli se réfère à Don Diego Saavedra, illustre

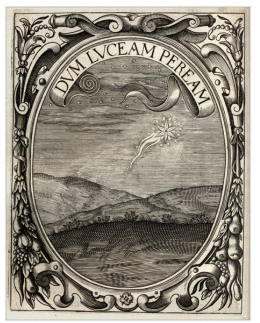
écrivain et homme politique espagnol contemporain qui place une fusée dans le ciel avec la devise DUM LUCEAM PEREAM, qui peut s'interpréter : «Je vais avancer aussi longtemps qu'il y a de la lumière-autant que je le pourrais... \18, Glorieux principe en effet. Poursuivant dans cet esprit élevé, voici la vie d'Agricola d'après Tacite : homme de bien, solide dans une longue gloire et enfin, la lumière couronnant certains lettrés.

$\mathbf{4 5} 5^{\mathbf{5 3}}$ Les fusées ne sont pas permanentes; elles ont une fin ; elles achèvent souvent leur parcours dans un fracas, en faisant des éclairs. Apparait ici le mot "folgoretto"mentionné dans le titre même de ce chapitre VII. Cette réalité est prise en compte avec la devise PERIT CUM SONITU, que le père Ménestrier inclus dans son livre des devises : «Elle se détruit avec bruit 》, formule souvent utilisée à la mort des personnages célèbres.

$\mathbf{4 6}^{53}$ La fusée vigoureuse monte aux étoiles, tant que le feu prédomine en elle, mais immanquablement le feu cesse ; alors elle dérive à terre, souvent en vagues de feu... Alors que la ferveur de l'esprit vit en nous, nous apportons davantage et nous arrivons à l'amour sacré de Dieu ; nous espérons porter tous les grands progrès spirituels. Lorsque manque la ferveur de la charité envers Dieu «il se précipita des hauteurs sublimes ».

\footnotetext{
${ }^{18}$ Image et Interprétation cueillies sur Internet.
} 
$47^{53}$ Cureuse référence à un évêque du XIIIe siècle, Filippo de Pistoia, dont la biographie est fort développée sur Internet. "Silencieux", il aurait peint sur un panneau, une fusée avec la mention : UN ANNEAU DE FEU... « Appliquer aux personnes rancunières » ( ?) Le texte n'est pas clair mais le premier mot caractérisant ce paragraphe est bien «Iracondo : Irascible, coléreux », dit le dictionnaire. Quoiqu'il en soit la suite revient à l'esprit du feu et à ses relations avec l'Esprit-saint en citant ce verset célèbre des Actes des Apôtres : «Tous furent alors remplis de l'Esprit saint et commencèrent à parler en d'autres langues selon que l'Esprit leur donnait de s'exprimer 》

$48^{53}$ Le paragraphe est consacré aux vertus cachées. À l'intérieur de la fusée, tout est calme, mais quand le feu se manifeste durement, il répand alors des flammes très claires autour d'elle. La devise est ERUMPANDO NITEBIT (Sortir à nouveau). Ménestrier nous vient de nouveau en aide en commentant ainsi : "Une fusée dont le feu ne parait pas encore ERUMPTO NITEBIT. Quand elle partira son feu se fera voir (pour une personne qui ne se fait connaitre qu'en se retirant) » Alors la vertu du juste, restée cachée jusque-là, se découvrira tel que l'Évangile de Luc le proclame : « C'est pourquoi tout ce que vous aurez dit dans les ténèbres sera entendu au grand jour, et ce que vous aurez dit à l'oreille dans les pièces les plus retirées sera proclamé sur les toits. »

$49^{53}$ Pour terminer ce chapitre consacré au feu des fusées, Picinelli cite cette devise : TANTUM CREPITUS (Seulement une explosion), commentée ainsi par Ménestrier : «Un soufflon ou pétard-TANTUM CREPITUS-Ce n'est qu'un peu de bruit (pour un fanfaron) » Le paragraphe est intitulé : Bavard ignorant.

\section{Échecs}

\section{Chap. VIII}

$\mathbf{5 0} \mathbf{5}^{\mathbf{5 3}}$ «Ce jeu précis (contrairement à beaucoup d'autres comme jeter des dés), dépend totalement du seul jugement et de la prudence du joueur c'est pourquoi les échecs ont de bonnes raisons d'avoir comme devise : AUCUN SORT. Idée de la personne qui a fondé l'espoir de ses avantages non dans une faveur externe mais uniquement sur le bien-fondé de ses vertus et dans l'opération de sa propre sagacité et prudence...»

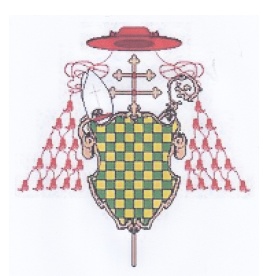

Board Game Studies Journal 11, pp. 1-52 DOI $10.1515 /$ bgs-2017-0001 
Éloge du savoir : une seule vertu «Mon bon travail, pas la chance. »

Avec cette même réflexion en l'honneur de Mgr Alfonso Litta, archevêque de Milan, montrant un échiquier sur le blason de sa famille illustre où fut ajoutée la devise INTELLIGENCE NON SORT, inférant que le Cardinal, ne le fut pas au profit de la chance, au hasard, mais par le mérite de son talent ; il est devenu honoré ; promu à la tête de l'Eglise milanaise.

$\mathbf{5 1} \mathbf{5 3}^{\mathbf{5}}$ Alors que le premier paragraphe met en évidence la valeur propre du joueur d'échec et son développement personnel, celui-ci illustre ses relations avec l'exercice militaire : "Présupposons, que ce jeu est un portrait des batailles rangées, trouvant en lui, les tours, et les cavaliers, et les fantassins, et les fous, etc...» Une occupation relevant de l'exercice élevé de vertu et de bravoure. Picinelli cite un passage d'histoire décrivant l'existence des soldats romains et montre comment le jeu d'échecs peut développer l'excellence.

$\mathbf{5 2}^{\mathbf{5 3}}$ Long paragraphe observant pour commencer que toutes les pièces ont vocation à prendre le Roi ; d'où la devise TRAVAIL POUR TOUS, enseignant que toutes nos souffrances, nos paroles et les opérations qui doivent être commandées pour l'acquisition des vertus, la jouissance et la possession de Dieu, correspond au verset célèbre de l'Évangile de Matthieu : «Tu aimeras le Seigneur ton Dieu de tout ton cœur, de toute ton âme et de tout ton esprit. »

Le second thème fondamental ici, est la propriété que possèdent les pions d'obtenir la puissance de la Reine, quand ils parviennent à l'extrémité $\mathrm{du}$ tablier. C'est alors la devise : QUOUSQUE REGNET - JUSQU'OÜ REGNER. "Les pions avançant progressivement peuvent obtenir le nom et les prérogatives de la Reine... \D'où une méditation sur les degrés qu'un ecclésiastique doit, ou peut, lentement gravir pour parvenir à la dignité de Cardinal ; l'exemple de la famille Litta est de nouveau proposé. « Sur le tablier quadrillé les mains laborieuses et l'ingéniosité perspicace beaucoup avancent à la fin qui font l'acquisition du Royaume... chaque âme devrait ainsi avancer jusqu'aux bénéfices de l'éternité et au glorieux Règne. »

$\mathbf{5 3}{ }^{\mathbf{5 3}}$ Poursuite de l'idée exprimée dans le paragraphe précédent en prenant l'exemple du Signore Nicolo Crasso, intellectuel et politique Vénitien, pour exprimer une véritable mutation.

$\mathbf{5 4} \mathbf{5 3}^{\mathbf{5}}$ Donner l'échec au Roi avec les pions peut être qualifié de RARE. . Picinelli, illustre cette situation avec un extrait du livre de Pietro Maffeo concernant les légendes et l'histoire des Indes.

$\mathbf{5 5} 5^{\mathbf{5 3}} \mathrm{Il}$ est question des parties de très longue durée. Comment Fabio Massimo a opéré de cette manière lente, en attendant les occasions de gagner. Les mots dans la marge sont: Maturité-Espérance.

$\mathbf{5 6 ^ { 5 3 }}$ Un éminent joueur de Padoue a placé le roi dans le "roccato" avec

Board Game Studies Journal 11, pp. 1-52 DOI $10.1515 /$ bgs-2017-0001 
les mots : «protecteur de victime ». Notons que les règles modernes du jeu s'imposent à cettef époque et que le Roque a pris naissance il y a moins d'un siècle. Picinelli veut donner au dernier paragraphe une tonalité essentiellement spirituelle en écrivant dans la marge «Nom de Jésus » Ainsi le roi des échecs sera en sécurité « quand il évoquera le saint nom de Jésus, beaucoup plus que par la valeur de toutes ses terres... \Sachant que le nom du seigneur est une Tour forte, également avec la protection de la Vierge Marie qui est « un mur stable et ferme. »

\section{TOUPIE}

\section{Chap IX}

$\mathbf{5 7 ^ { \mathbf { 5 3 } }}$ Les coups lui donnent de l'âme, cette citation de l'Énéide, appliquée au mouvement de la toupie, ouvre le dernier chapitre consacré aux jeux. Les mots du paragraphe sont sans équivoque : «Fouet donné aux enfants pour une éducation rigide »! L'exemple des spartiates où les grandes corrections se donnent à l'autel pour l'édification de tous, renforce encore ce caractère.

$\mathbf{5 8} 8^{\mathbf{5 3}}$ Punition, Travail... Poursuite du même

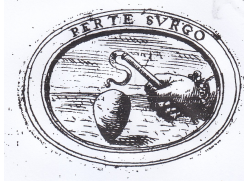
thème des punitions corporelles, avec la devise PER TE SURGO - POUR TE DRESSER ... L'image cicontre est empruntée à Bargagli. « Elle tomberait la toupie si le coup de fouet ne l'incitait à la vertu... » Un verset des Proverbes confirme : «Baguette et réprimande procurent la sagesse / L'enfant laissé à lui-même est la honte de sa mère » Jérémie renchérit : «Tu m'as corrigé, j'ai subi la correction comme un jeune taureau non dressé. Fais-moi revenir, que je revienne, car tu es Yahvé, mon Dieu!» L'évangile de Luc avec la parabole de l'enfant prodigue est cité, et aussi la devise donnée à la toupie par Carlo Besso : VERBERE SURGET-VERGE $L E V E E$.

$59^{53}$ Sans le citer, Picinelli, reprend la devise présente dans le Teatro d'imprese de Giovanni Ferro : STAT MOTU-FIXE EN MOUVEMENT. Ceci demande une action soutenue et l'image montre la lanière du Fouet, instrument de cet entretien continu. Image de l'agitation et de l'instabilité de la vie humaine. Grégoire de Naziante a exprimé cette volatilité et cette mutation à propos du cerceau, d'une stabilité trompeuse qui se déroule avec la vie

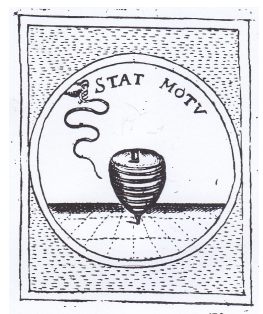


brève où s'annulent le haut et le bas, alors qu'il

semble rester immobile mais dont le mouvement doit être entretenu pour ne pas tomber.

$60^{53}$ À propos de la toupie attachée avec le fil autour d'elle, Bargagli fut amené à dire : VINCIR UT ERIGAR - ATTACHÉE QUOIQUE DRESSÉE ... Ceci est applicable aux saints martyrs pour lesquels les chaines n'ont pas de prise sur la sagesse divine. Citation de l'Ecclésiastique : «Présente ton épaule à ton fardeau, ne sois pas impatient de ses liens. »

$61^{53}$ La toupie enfermée dans sa corde introduit la devise VINCIOR UT VINCAM-ENCHAINÉ VICTORIEUX ; Nouvelle allusions aux martyrs serviteurs de Dieu, dont les mains et le corps enchaînés sont à la source de leur victoire. À peine saint Paul se trouva lié et enchaîné au fond d'une prison que, nous disent les Actes des Apôtres : « Tout à coup, il se produisit un si violent tremblement de terre que les fondements de la prison en furent ébranlés. À l'instant toutes les portes s'ouvrirent, et les liens de tous les prisonniers se détachèrent. »

$\mathbf{6 2} \mathbf{2}^{\mathbf{5 3}}$ Cette vignette provient de L'édition 1653 et ne sera pas reprise par la suite. Dans l'ensemble

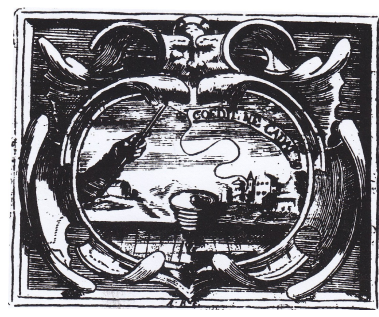
de l'ouvrage les illustrations sont très rares, ce qui donne un prix supplémentaire à celle-ci. Nous voyons une toupie en rotation avec la main tenant le fouet qui l'anime. Lorsque la vitesse de rotation diminue en risquant de la faire tomber, l'enfant intervient avec son fouet, est-il rappelé. La devise COEDIT NO CADAT rappelle, insiste Picinelli, que Dieu, flagellé, n'est pas tombé. Dans sa deuxième épître aux Corinthiens, saint Paul peut écrire :

«Et pour que l'excellence même de ces révélations ne m'enorgueillisse pas, il m'a été mis une écharde dans la chair, un ange de Satan chargé de me souffleter - pour que je ne sois pas plein d'orgueil. »

$63^{53}$ Toujours sur le thème du fouet indispensable à la toupie pour qu'elle se tienne droite, Picinelli termine ce chapitre en poussant sa démonstration à sa limite. Il nous parle d'un ami de Carlo Bosso, soumis à de violentes persécutions, qui a résisté si bien que les effets se sont révélés contraires : « Il reste debout plus longtemps qu'auparavant, et vigoureux, et fort, figure droite de la toupie... Ceci est bon pour établir l'armée des opérations vertueuses pour la gloire de Dieu.» 


\section{FILIPPO PICINELLI}

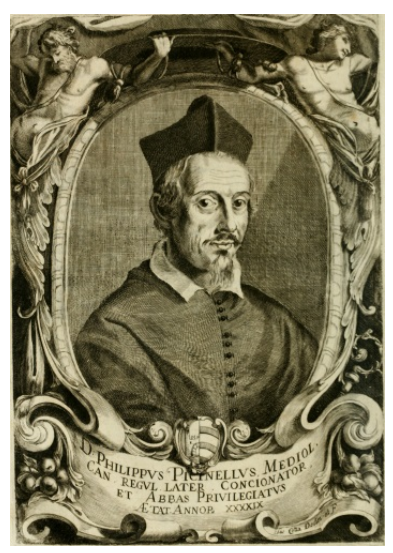

Filippo Picinelli nous est devenu proche. Avant d'aborder les autres éditions de son ouvrage, cherchons un peu à mieux le connaitre. L'encyclopédie Wikipédia n'est guère prolixe. Né en 1604, décédé en 1678 ; Il fut chanoine régulier de Saint-Augustin de la Congrégation de Latran, un ordre où il est entré à l'âge de dix ans quand il a commencé ses études au collège. Il étudie la philosophie et la théologie. «Il pensait que le monde créé par Dieu pouvait être lu comme un livre de symboles. C'est guidé par cette conviction qu'il entreprit son célèbre livre d'emblèmes, ouvrage d'ambition encyclopédique de plus d'un millier de pages, connu sous le titre de Mundo simbolico, et qui fut publié pour la première fois en 1653 à Milan par Francesco Mognagha. »Ce portrait provient de la première édition italienne de 1653 et, en agrandissant, on peut lire le texte du cartel : « D. Philippus Picinellus Medio 19 Can regul later Concionator et Abbas Pivilegiatus Aeta Annor XXXXIX»-《Docteur Phillipus Picinellus-Milan-Chanoine régulier du Latran - Prédicateur et Abbé privilégié - Temps de la vie : 49 ans ».

Le voici donc à 49 ans, en 1653. Sur cette gravure dont l'encadrement est particulièrement soigné, dominé par un couple tenant levé le voile qui sans eux nous le cacherait. Ses armoiries discrètes ne parlent guère. Il n'est pas du genre Chanoine arrondi et truculent comme certaines imageries se plaisent à les moquer parfois. Il pourrait être un surveillant dans un collège observant ses élèves, mais son œil droit, tout rond, bien placé sur l'axe central de l'image, regardant fixement en face de lui, nous dit comment il scrute le monde. Ce portrait ne sera pas repris dans les éditions suivantes.

En voici un autre, plus tardif ; il se trouve

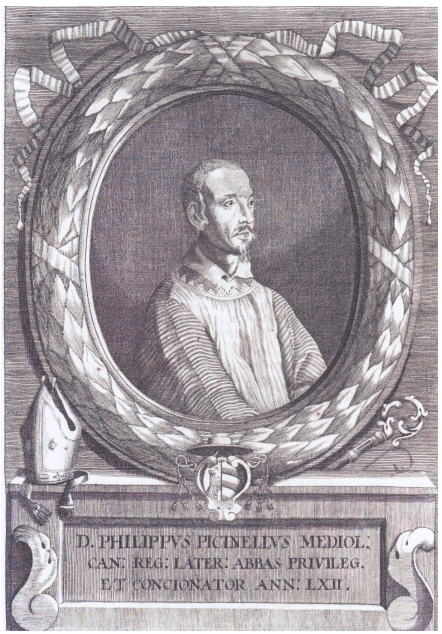
dans un des livres dont nous allons parler, un

${ }^{19}$ Mediolanum : (Milan) ville de la Gaule transalpine. 
recueil de sermons sous le titre «Lumina reflexa ». Le portrait le représente à l'âge de soixante-deux ans ; il a conservé sa petite barbiche mais a perdu de sa superbe - selon l'expression consacrée. Nous sommes en 1666 ; il travaille à la seconde édition de son Mundo simbolico qui paraitra trois ans plus tard, largement augmentée. Son statut s'est élevé dans sa communauté, signalé par la présence de la mitre et de la crosse ; il possède les prérogatives d'un «Abbé mitré ».

Sept ouvrages sont signalés dans sa notice Wikipédia, en plus de son Mondo simbolico. Il est difficile de leur attribuer un ordre chronologique car les éditions numérisées ne sont pas toujours les premières. En voici les pages de titre dans l'ordre alphabétique donné sur la notice.

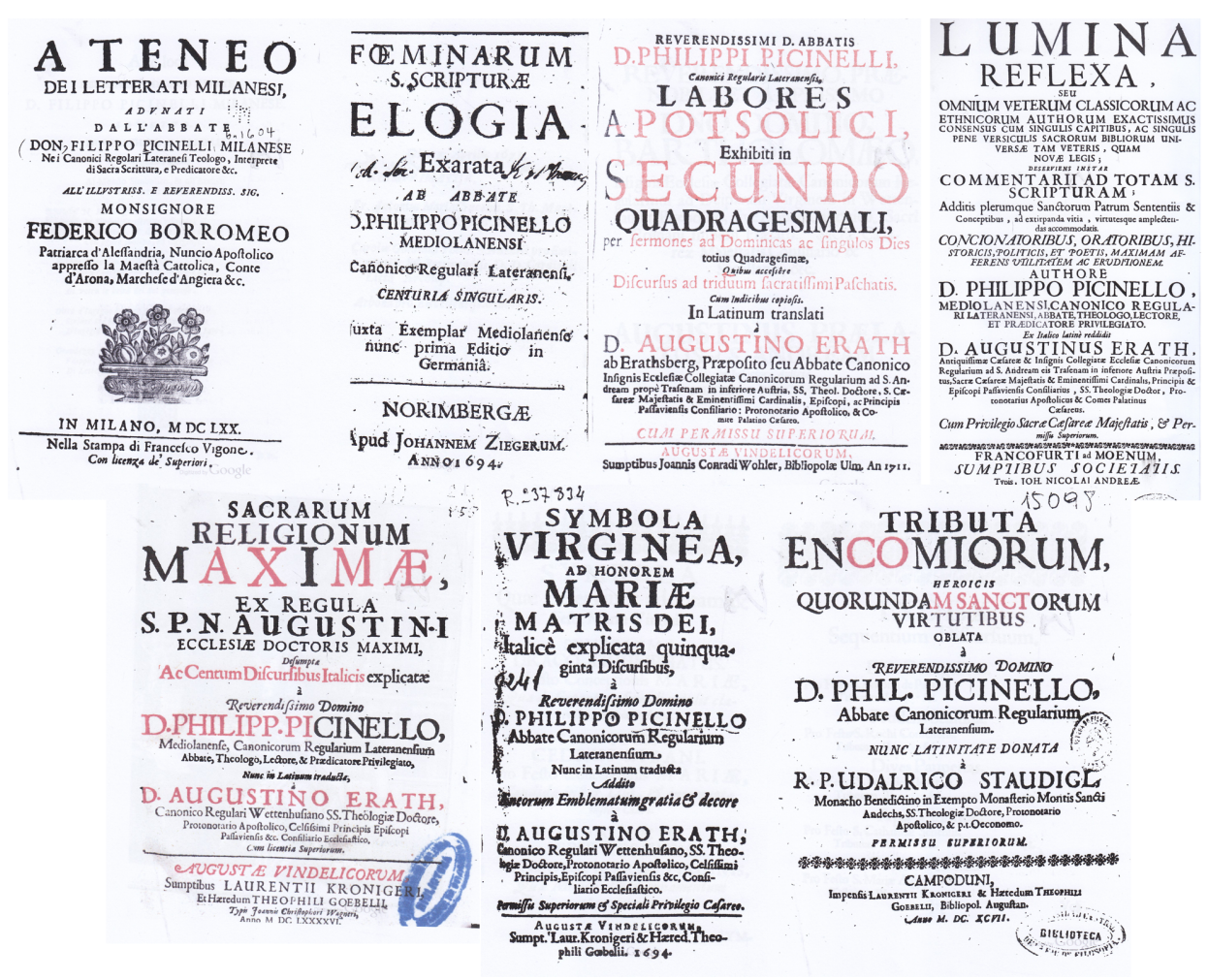

Indépendamment des mentions elles-mêmes, un nom intrigue qui figure à plusieurs reprisses sur ces pages de titre, celui d'Augustin Erath. Il est important car on le retrouvera sur l'édition latine du Simbolico italien qui devient Symbolicus après traduction, avec quelques transformations dont il faut bien se demander si elles sont de Picinelli ou de lui-même. Cet Augustin Erath est né en 1648 et mort en 1719 . Il a donc à peu près quarante ans de 
moins que Picinelli et avait donc une trentaine d'années lors du décès de celui qui fut pour lui manifestement proche, pour ne pas dire un maître. Il est aussi Chanoine régulier et se dévoua donc par la suite pour faire connaître l'œuvre de Picinelli, en traduisant en latin des volumes déjà publiés et, peut-être des textes inédits.

\section{ATENEO dei letterati milanesi}

Ouvrage de 580 pages qui réunit des notices concernant les intellectuels ayant marqué la vie de Milan. Le classement des personnalités se fait curieusement par ordre alphabétique des prénoms. . . et l'on trouve Picinelli lui-même à la page 192, entre Filippo Meda et Filippo et Filippo Pedrovano. Belle aubaine qui sera présentée plus loin. Le livre est édité en italien à Milan en 1670, peu avant la mort de son auteur. Il est dédié à Monsignore Federico Borromeo, patriarche d'Alexandrie, Nonce apostolique ... On trouve sa notice page 181, particulièrement étendue - comme il se doit - puisqu'elle couvre trois pages et demi (d'autres ne dépassent pas quelques lignes)

\section{Fœ inarium s. scripturæ ELOGIA}

Petit livre de 220 pages composé d'une suite de poèmes faisant l'éloge de personnages féminins empruntés à l'Ancien et au Nouveau Testament. Édité à Nuremberg et en 1694, après la mort de Picinelli, mais il s'agit d'une réimpression de l'édition milanaise de 1671.

\section{LABORES APOSTOLICI Exibit in Secundo quadragesimali}

Fort volume moyen format, d'environ 600 pages, contenant trente-huit sermons prononcés à l'occasion d'un carême, traduit en latin et paru en 1711 . L'édition ne comporte pas de mention pour une éventuelle parution antérieure en italien. Il comporte un index alphabétique des thèmes.

\section{LUMINA REFLEXA, Seu Omnium Veterum Classicorum Ac Ethnicorum Authorum Exactissimus Consensus...}

Ouvrage de 400 pages, daté 1702 ; réédition en latin d'une version italienne antérieure. Méditations à partir de textes empruntés à la Bible : Genèse, Exode, Lévitique, Nombre. C'est dans ce volume que se trouve le portrait de Picinelli âgé, reproduit plus haut.

Board Game Studies Journal 11, pp. 1-52 DOI $10.1515 /$ bgs-2017-0001 
Une place de choix est donnée en tête du volume à illustration ci-contre. Nous voyons la lumière venant de Dieu arriver sur le miroir d'une belle figure allégorique qui la renvoie vers le disciple prêt à la recevoir. En dehors du titre et du nom de l'auteur, plusieurs mots ou textes sont lisibles sur l'image agrandie. Le volume tenu par la femme est une BIBLE. En haut à gauche (autour du miroir) ; OMNE DE SURSUS [Tout d'en haut] En bas à gauche, on lit: UNUS ET MULTIPLEX [Un et multiple], tandis que deux volumes VIRGILE ET SÉNEQUE sont posés sur un support où se trouve écrit : LUMEN A SOLE [lumière du soleil].

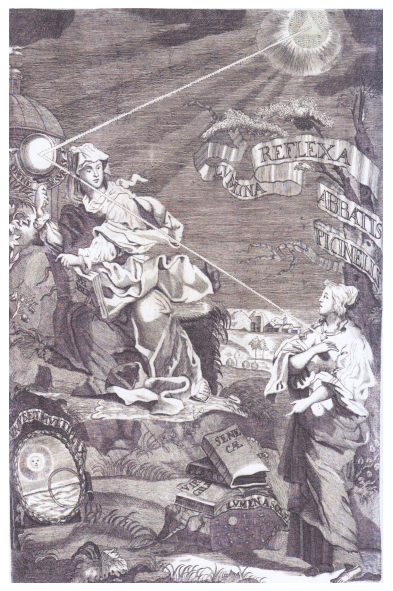

\section{SACRARUM RELIGIONUM MAXIMÆ, ex regula S.P.N. Augustini...,}

d'environ 700 pages. Contient cent entretiens relatifs à l'enseignement de Saint Augustin. Édition 1696 ; il est spécifié sur la page de titre qu'il s'agit d'une traduction latine de Augustin Erath. On y trouve un troisième portrait.

Est-ce Filippo Picinelli, portant sa mitre, cette fois dans sa bibliothèque, à sa table de travail, en train d'écrire, l'air inspiré (visible sur l'agrandissement car si l'intéressé tient bien la plume d'oie à la main, il regarde au loin...) ? À moins que ce

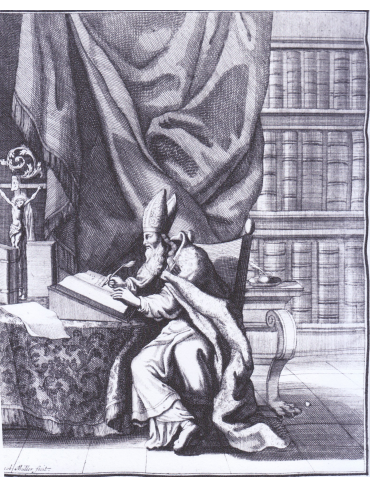
ne soit un hommage à saint Augustin... Comme les précédentes, cette gravure n'est pas signée.

\section{SYMBOLA VIRGINEA, ad honorem Mariæ matris Dei}

petit format, environ 780 pages, 1694. La dédicace est signée Augustin Erath. Le livre est composé de cinquante méditations consacrées à la Vierge Marie. Deux images figurent au début. La première étant un frontispice ; elle montre à la partie supérieure, un ange tenant une banderole portant une légende malheureusement difficilement lisible et en bas à droite,

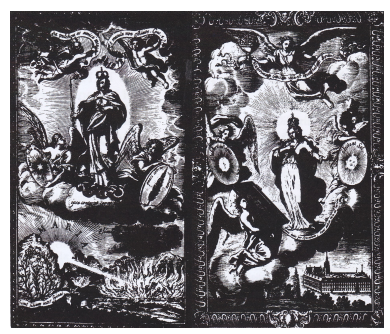


la représentation d'un couvent.

La seconde représente le Christ, avec également quelques textes mais surtout au milieu à droite un écu ovale ou est dessiné un arbre : « quasi cedrus exaltata », référence à un verset de L'Écclésiastique « J'y ai grandi comme le cèdre du Liban, comme le cyprès sur le mont Hermon »

\section{TRIBULATA ENCOMIORUM heroicis quorundam sancto- rum virtutibus,}

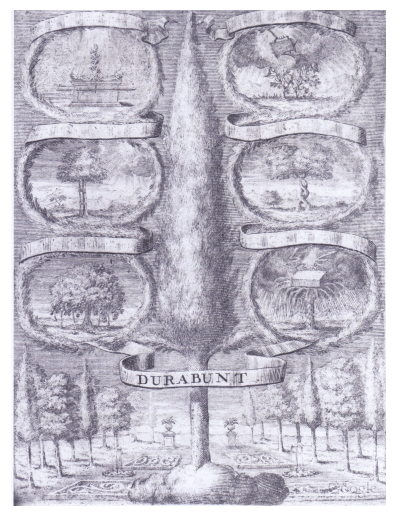

1696, environ 280 pages. Cette fois, la traduction latine n'est pas d'Augustin Erath, mais du Père Udalrico Staudigl, moine bénédictin. L'ouvrage propose une suite d'entretiens dédiés à des saints ou des personnalités religieuses éminentes. L'ouvrage s'ouvre sur cette gravure qui représente autour du cèdre mythique une série d'arbres marquant la durée et la Foi sous différentes formes.

Tous ces livres ont été publiés après la mort de Filippo Picinelli, décédé à l'âge de soixante-quinze ans. Ces rééditions nous disent le prestige considérable qui fut le sien en son temps. C'est le moment de ouvrir l'ouvrage Ateneo à la page 192 où se trouve la notice le concernant, écrite par lui-même.

FILIPPO PICINELLI : «Déjà le nom Picinellus ne porte en lui aucun anagramme, mais Penicillus, avec le rapport à la plume, au pinceau, trouve sa place dans cet Ateneo, consacré aux écrivains ; à l'imitation des historiens, des peintres et votre nom est peut-être un portrait. Veuillez, s'il vous plait, me permettre de parler à la troisième personne, à cet endroit, dans ce site à l'effigie de moi-même. Au jour du 21 novembre 1604, à Milan, il vient à la lumière. Mais la force est si faible que le baptême a lieu seulement le 25. Le curé de saint Eusèbe se plaint, car pendant quatre jours le baptême a été différé et l'enfant a couru le risque de terminer sa vie sans salut, sans le sacrement du salut. Francesco Gambaloita, grand caractère et Laura Casalini Merati, d'origine remarquable, furent les témoins de cette source sacrée. Alors, la puérilité passée et bien que ses goûts l'auraient porté vers la peinture et la poésie italienne, il apprend les bonnes Lettres. . . \ Après ces lignes d'introduction, Picinelli énumère dans une suite quelque peu lassante, les noms de ses professeurs et surtout la suite interminable des églises où il a prêché des carêmes, les noms des personnalités qui lui ont été bienveillantes, les travaux qu'il a entrepris. Il donne alors lui-même la liste de ses ouvrages

Board Game Studies Journal 11, pp. 1-52 DOI $10.1515 /$ bgs-2017-0001 
imprimés dans une suite que l'on trouve ci-dessous ; il a paru plus intéressant de la reproduire telle quelle.

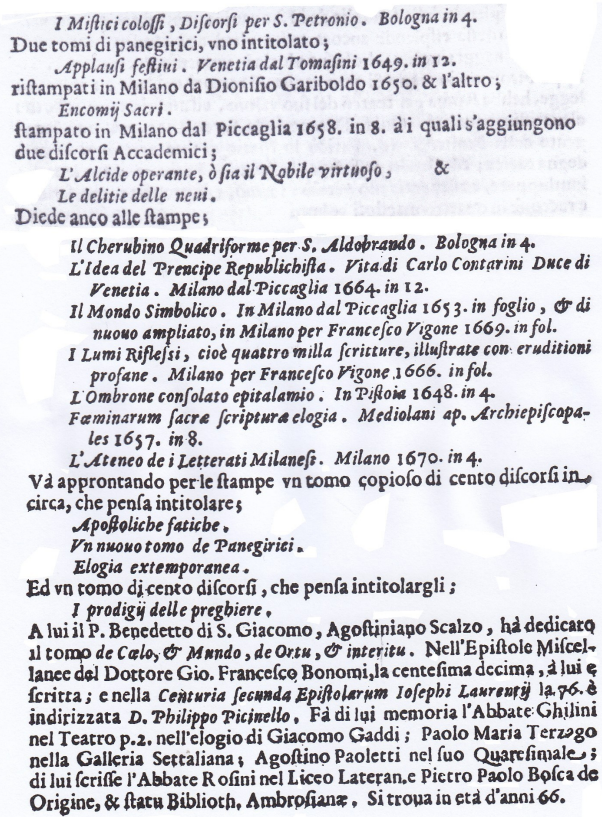

Terminons ce portrait succinct de Picinelli en citant ses ouvrages présents à la Bibliothèque Nationale de France :

Mondo simbolico s'y trouve dans ses éditions 1653 [572 pages] et 1669 [854 pages] mais une autre, pas encore repérée, est signalée en 1678 [650 pages] imprimée à Venise. En revanche, il ne se trouve pas ici d'édition latine.

Atenao dei letterati. . 1670

Lumi riflessi. . 1667

Symbola Virgince...(1694)

I Prodigi delle preghiere... (1672)

Surprise sympathique, d'autres livres, non encore rencontrés jusqu'à présent, sont également conservés. Les voici, avec leur notice :

Tributi di lode offerti all'eroiche virtù d'alcuni santi, dall'abbate D. Filippo Picinelli,... Parte terza de suoi Panegirici... [Texte imprimé] Publication : Milano : stampi di F. Vigone, 1675 Description matérielle : In- $4^{\circ}$, VIII-315 p. et l'index

\section{Prodigi delle preghiere spiegati in cento discorsi scritturali}


eruditi, morali, dall' abbate D. Filippo Picinelli,... [Texte imprimé] Publication : In Milano : stampa di F. Vigone, 1672

Description matérielle : In- $4^{\circ}$, pièces limin., 601 p. et l'index

Le Massime de i sacri chiostri ricavate dalla regola del padre S. Agostino, e spiegate in cento discorsi, studii senili dell'abbate D. Filippo Picinelli,... [Texte imprimé] Publication : In Milano : F. Vigone, 1678 ; Description matérielle : In- $4^{\circ}$, pièces limin., 577 p. et l'index

Davide musico armato, discorso... dal P. D. Filippo Piccinelli,... [Texte imprimé]

Publication : Bologna : C. Ferroni, 1640 ; Description matérielle : In- $4^{\circ}$, $22 \mathrm{p}$.

Les amateurs ont de jolies découvertes en perspectives. N'oublions pas sur le site Amazon, quelques titres réédités, en particulier Mondo simbolico ... On trouve aussi parfois une édition ancienne : Lors de la vente de la bibliothèque de Jean-Claude Carrière en 2014, l'édition latine de 1681 était estimée entre 800 et $1000 €$.

C'est le moment de revenir au chapitre sur les jeux, dans les éditions suivant la première. Auparavant, jetons un coup d'œil page 572 de celleci (1653), où est mentionné, comme il a été dit, un Additif. Il concerne le paragraphe 34, au début de Rachetta et sera intégré à cette place dans l'édition 1669. Le début est le suivant, nous l'avons vu : « La raquette porte les mots : ALLER MODÉRÉMENT LOIN. Cela montre qu'une très légère passion, mais puissante, peut nous aliéner la loi de la vertu. » Picinelli ajoute alors une citation de L'Imitation de Jésus-Christ : «Je confesserai contre moi mon injustice, je vous confesserai, Seigneur, mon infirmité. Souvent un rien m'abat et me jette dans la tristesse. Je me propose d'agir avec force; mais à la moindre tentation qui survient, je tombe dans une grande angoisse. Souvent c'est la plus petite chose et la plus méprisable qui me cause une violente tentation... 》

N'oublions pas de tout ramener à Dieu, nous dit notre Abbé.

Board Game Studies Journal 11, pp. 1-52 DOI $10.1515 /$ bgs-2017-0001 


\section{Édition 1669}

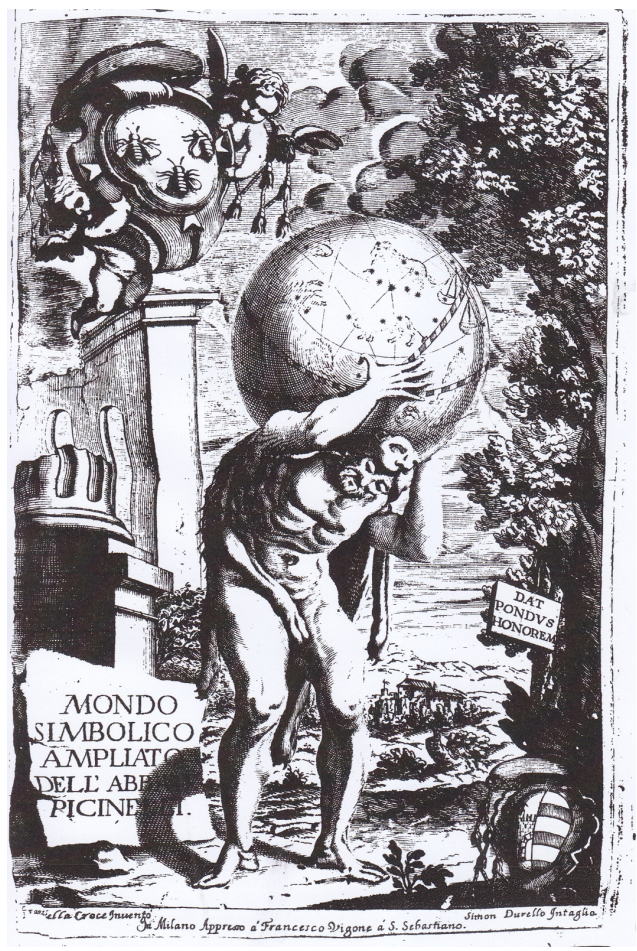

1653

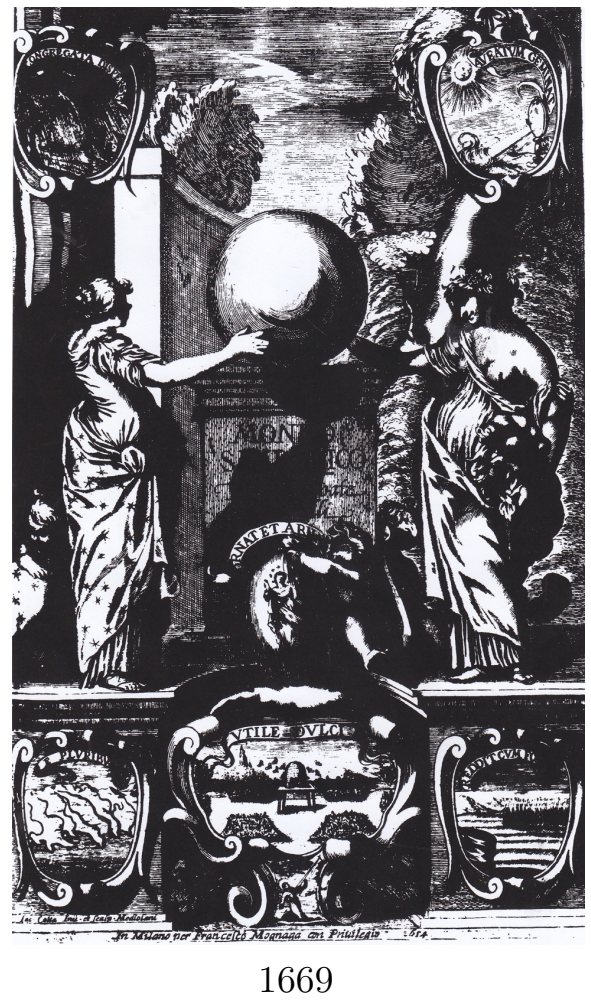

1669

La différence entre les deux pages d'ouverture montre combien l'auteur semble plus assuré de la puissance de son ouvrage. En 1653, deux jeunes filles présentent le globe terrestre (Mundo) presque timidement ; en dessous un ange tient, dans un ovale, une figure de la vierge Marie et quelques devises accompagnent les cartouches ; la principale couronne l'image d'un jardin où l'on voit une ruche et des abeilles volant autour : UTILE DULCIS témoigne d'une véritable modestie. Le ton change quinze ans plus tard, car c'est la figure d'Atlas lui-même (Picinelli ?) qui porte non seulement le monde sur ses épaules mais l'univers avec son firmament d'étoiles. Les abeilles ont quitté le jardin pour se fixer sur un blason et des armoiries en bas à droite sont celles de Picinelli, que l'on a pu apercevoir déjà sur des illustrations reproduites plus haut.

La rédaction des deux dédicaces propose le même saut, de la modestie à l'assurance. En 1653 l'ouvrage est dédié « Alla Gran Madre d'Iddio, MARIA semper virgine »; en 1669 la dédicace s'adresse «All' Eminentiss Principe Il Sig. Cadinal CARLO BARBERINI», un haut dignitaire, alors à Rome. 
S'ajoute à cela un hommage sous la forme d'un sonnet : "All'Eruditissima Penna del Rev. Padre Abbatte D. FILIPPO PICINELLI-Per la seconda impressione del suo Mondo Simbolico - SONETTO di D. Carlo Pietrasanta Ch. della Congregat di Somasca. »Cette congrégation est au service des pauvres. Carlo doit être un parent de Silvestro Pietrasanta, jésuite, dont son ouvrage sur les symboles a été consulté en proposant plusieurs images intéressantes, dont celle du dé posé sur une table recouverte. Sonnet sympathique comme il se doit, bel hommage à l'ouvrage et à son auteur sur un ton d'admiration sincère. La mention "seconde impression" est à noter.

Cette nouvelle édition porte la mention AMPLIATO et l'amplification, en effet, est notable : environ 800 pages en 1653 et 1100 en 1669. Le nombre des Livres n'a pas changé : vingt-cinq. Les Jeux restent placés au Livre dixhuit. Les neuf jeux considérés plus haut sont les mêmes et forment toujours neuf chapitres. En revanche le nombre des paragraphes a augmenté d'une édition à l'autre : 63 en 1653 et 79 en 1669. Cette augmentation tient à des textes ajoutés, mais également au fait que certains paragraphes un peu long dans l'édition 1653 ont été scindés en deux en 1669. Ces textes ajoutés d'une édition à l'autre ne modifient rien d'essentiel ; ils sont l'occasion de nouvelles citations et de nouvelles devises.

\section{DÉS}

$5^{69}$ Picinelli met un accent violent sur les risques du jeu : « Jeté sur la peau des tambours des armées, avec un seul coup mortel...»Analogie avec un coup d'œil pouvant porter l'âme vers les ruines extrêmes ; il illustre son propos avec deux citations : la première venant des Lamentations de Jérémie «Mon œil me fait souffrir, à cause de toutes les filles de ma ville» et le second, de Virgile, célèbre : «Ut vidi ut perii-Je te vis, je t'aimais »

\section{FARINACCIO}

$\mathbf{1 0}^{\mathbf{6 9}}\left[\mathbf{9}^{\mathbf{5 3}}\right]$ Ce complément de quelques lignes ajoute une conclusion à ce chapitre et porte en marge les mots «Travail utile»; Picinelli prend en compte la nature même de ce dé dont toutes les faces sont blanches, sauf une qui est noire. « Les parties blanches du Farinaccio ne sont ministres d'aucun bonheur; le noir est celui qui multiplie la satisfaction du joueur ; ainsi le père D. Filippo Maria Gallina, mon Confrère, dit : IN NIGRO SORS-SORT EN NOIR. Parmi les blancs, les joueurs ont un indice de disgrâce équitable; mais les noirs, signes de malheur, sont promus au bonheur béat... Renvoi à la spiritualité avec Saint Augustin quand celui qui possède, mérite d'être

Board Game Studies Journal 11, pp. 1-52 DOI $10.1515 /$ bgs-2017-0001 
encouragé et celui qui souffre doit être consolé.

\section{BALLE}

$16^{69}$ Paragraphe ajouté sur le thème : Pauvreté apostolique. « Comme la balle avec une agilité admirable traverse les vastes provinces, le saint Évangile est apporté partout... »; et la vie est assurée à la sueur du front et le travail des mains. Citation d'un extrait des Actes des apôtres : "Argent, or ou vêtement de personne, je n'en ai convoité. Vous savez vous-même qu'à mes besoins et à ceux de mes compagnons ont pourvu les mains que voici. » Pour conclure avec cette phrase à l'image de la balle : «Il est qu'errance, pour atteindre un point de la terre. »

$\mathbf{2 0}^{\mathbf{6 9}}$ Paragraphe ajouté sur le thème Travail exaltant. « Lorsque la balle est lancée à la terre, la force de cette chute, la fait agilement rebondir vers le ciel. Je peux dire DELECTA SUSTOLLOR, CHARME DE L'ÉLÉVATION ...» Ainsi pour l'âme abattue dans l'univers. La chute appel un rebond. Exemple de saint Paul tombé au sol qui appelle vers le ciel ou le fils prodigue « immergé dans la fosse à lisier qui aspire à la maison de son père. »

$29^{69}$ Paragraphe ajouté, en conclusion du chapitre consacré à la balle, sur le thème Effort joyeux. Exemple des grosses boules en bois cerclées de fer qui se trouvent avec l'inscription IN LABORE SOLATIUM ; référence à un couplet du Veni sancte spiritus : "Dans le labeur, le repos, dans la fièvre, la fraîcheur, dans les pleurs, le réconfort.»

\section{PALLONE BRACCIALE}

$\mathbf{3 2}^{\mathbf{6 9}}\left[\mathbf{2 9}^{\mathbf{5 3}}\right]$ Prolongation du paragraphe 29 de l'édition 1653, portant dans la marge l'indication Fierté disciplinée. Les coups du bracelet frappent la balle pleine de vent à laquelle est associée la formule INFLATUS PERCUTITURGONFLÉ FRAPPÉ...qui rappellent les mots de saint Augustin quand il évoque certains enflés d'orgueil, gonflés avec fierté, mais loin de Dieu.

$33^{69}$ Ce nouveau paragraphe traite du pécheur obstiné. Il est question du pécheur superbe, bien qu'il soit frappé, semblable à la balle, ne laisse rien oublier de son importance ; les coups ne le calment pas... Ces misères, déplore Jérémie : «Tu les as frappé ; ils n'ont rien senti. Tu les a écrasés : ils ont refusés la leçon. Ils se sont faits un front plus dur que le roc, ils ont refusé de se convertir.»

$35^{69}$ - Nouveau paragraphe. Le ballon gonflé est à l'image du monde empli d'honneurs et de richesses, gonflé et enflé : une bouteille congelée. 
$36^{69}$ - Nouveau paragraphe. Rien n'est perdu, il peut y avoir aussi un pécheur pénitent...

\section{BRACCIALE}

$38^{69}$ - Nouveau paragraphe en introduction de ce chapitre ; il précède le $\mathbf{3 3}^{\mathbf{5 3}}$. Le bracelet est ici évoqué comme une « chance coupable et une disgrâce ; et la disgrâce invite les gens à fuir.» La fuite se poursuit contre l'homme comme si elle était un ballon. «La mort va bientôt venir après lui... » dit Horace. Cette entrée en matière pour ce jeu, dit le peu d'estime de Picinelli à son égard.

\section{FUSÉE, ÉCLAIR, PÉTARD}

$43^{69}\left[3^{53}\right]$ Complément de la fin du premier paragraphe consacré à ce chapitre. Comme si le début pouvait faire peur, Picinelli semble atténuer et montrer qu'il s'agit bien d'un jeu. Un concept qui a valu le titre QUIA FERVIDUS INTUS - ICI BOUILLANT AU-DEDANS . . « Les étoiles sont à l'intérieur du tube de pulvérisation; Pire encore, cela vole, quand le cœur est chaud avec l'amour. » INNOXIA TERRENT_EFFRAYANT SANS FAIRE DE MAL. Symbole de menaces innocentes.

$\mathbf{4 6}^{\mathbf{6 9}}$ [39 $^{\mathbf{5 3}}$ ] Quelques lignes à la fin du paragraphe 46 (1669) qui est 39 (1653). Une devise : AD SYDERA CURSUM-POUR LES CORPS CÉLESTES. « Le folgoretto, tout droit dans le ciel, et ceci pour désigner l'affection contemplative et l'esprit d'élévation en Dieu »

$49^{69}$ Trois nouveaux paragraphes courts sont ajoutés ; celui-ci est le premier avec en marge Élévation du travail ; «Pour une fusée allumée, actuellement transportée dans le ciel au-dessus de jeunes mariés...»Vulcain apparait alors dans une devise, tandis qu'un extrait d'une tragédie apostrophe : «Vous courrez à travers un héros de feux clignotants » La conclusion étant laissé à saint Laurent, martyr sur un gril, remerciant le Seigneur.

$\mathbf{5 0} \mathbf{6 9}^{\mathbf{9}}$ Paragraphe concernant l'hypocrisie de ceux qui simulent une montée au ciel et leur façon de croire qu'ils sont parvenus à l'Olympe.

$51^{69}$ Tentatives avortées. Il est raconté comment le Folgoretto-rongé par le vent - est rappelé du ciel vers la terre.

$\left.\mathbf{5 9} \mathbf{6 9}^{[\mathbf{4 9 3}}\right]$ Court passage ajouté au début du paragraphe numéroté 49 dans l'édition 1653, sur le thème de l'insolence rabattue. Voici le corps d'une fusée «éclatée et couchée sur le sol » Furieuse défaillance décrochée par le symbole d'un tir vers le bas... Une citation de Sénèque, dit à peu près : 
«Ceci commence par un grand bruit, puis, usés avant leur temps, il n'y a rien d'autre, que la cruauté, et les nouveaux types de punitions à venir...»

\section{ÉCHECS}

$6^{69}$ [Deux paragraphes ajoutés $64 \& 65$ entre $52 \& 53$ de l'édition 1653] Cour désintéressée, se lit dans la marge. «Parce que l'éminentissime Archevêque Litta porte un échiquier sur son blason, sur lequel cependant, il n'y a pas de pièce d'échecs, je lui ai donné la devise LATRUNCULI PROCULESPIONNÉ DANS LA DISTANCE ? Inférant avec un gracieux malentendu qu'il a tenu à l'écart de sa Curie les ministres concernés et radins. Ainsi, dans son cour, il reçoit les conseils donnés par l'empereur Basile à son fils : "Prendre pour consultant un interlocuteur expérimenté, prudent, pénétrant, etc. Certains avec un seul esprit, incorruptible, invisibles et ne cherchant aucun profit." »

$65^{69}$ Dans les échecs, lorsque tout le monde termine le jeu, à la fois le roi et la reine, les fous et les pions, tous sont jetés dans un sac, invitant Henri Engelgrave à dire OMNES EODEM COGIMUR - TOUS LE MÊME SAC, pour montrer que les hommes nobles ou plébéiens, riches ou pauvres, seront les mêmes appelés à l'obscurité de la tombe et aux entrailles caverneuses de la terre, comme le dit Horace : "Riche ou pauvre, fils du puissant ou du dernier des citoyens, sans autre abri que les cieux, tu n'en seras pas moins la victime de l'inexorable Pluton... » Les pièces utilisées dans le jeu d'échecs, le Roi, la Reine, les tours, les cavaliers, les fous, les pions... tous se déplacent avec des mouvements différents et sont ainsi être au service de tout le monde pour la victoire. Ainsi dans les Académies, bien qu'il se manifeste une grande variété de talents, tous peuvent arriver à la victoire, c'est-à-dire à l'acquisition de vertus. Ainsi dans l'église de Dieu, même si elles servent d'autres armées, d'autres cloîtres, d'autres dans la vie active, d'autres plus contemplative, tous cependant sont appropriés pour obtenir la victoire et la Belle couronne.

\section{TOUPIE}

$\mathbf{7 1}^{\mathbf{6 9}}$ [57 $^{\mathbf{5 3}}$ ] Complément au paragraphe 57 de l'édition 1653. Picinelli insiste sur l'importance des punitions corporelles ; il prend l'exemple de l'éducation sévère subie par les Spartiates, constituant la raison de leur courage. Une formation dure, comme il est souligné dans la marge - Éducation rigidedonne la force de résister aux persécutions.

$\mathbf{7 2}^{69}$ Rien ne vient de la toupie attaquée par beaucoup. Elle propose 
comme devise VOLVITUR, NON PROGREDITUR - MOUVEMENT IMPRODUCTIF. A l'image de chaque individu banal, animé par l'ambition, par la convoitise, par l'intérêt, n'est qu'un agité sans utilité.

\section{LES ÉDITIONS LATINES}

Même s'il avait certainement conscience de sa valeur, Filippo Picinelli aurait peut-être été étonné de son audience après sa mort. La première édition qui s'est dévoilée par surprise, lors de la recherche sur la fameuse devise SEMPER JACTARIUS- SEMPER ERECTUS est en deux volumes, datée 1715, mais il y en a d'autres auparavant où MONDO SIMBOLICO devient MUNDUS SYMBOLICUS, dans une traduction du chanoine Augustin Erath.

Deux ou trois ans après la mort de son auteur, parait en effet la première édition latine, en 1681. Elle en un seul volume - environ 1300 pages-mais possède déjà les deux parties qui seront reliées séparément par la suite. Plus tard viendront donc les éditions en deux volumes, en 1683 et 1715, mais d'autres sont signalées à Milan, à Venise, ailleurs encore. Même si les tirages ne dépassaient pas de beaucoup les mille exemplaires à chaque fois, cela représente une belle réussite.

On trouve page suivante le frontispice de l'édition 1681. Atlas portant l'univers sur ses épaules a disparu ; on revient à deux femmes portant le globe, mais elles ont perdu la douceur des débuts ; elles sont devenues des dames aristocratiques. D'ailleurs deux blasons complexes figurent, que les spécialistes en héraldique sauront déchiffrer. On retrouve la petite image d'origine avec la ruche dans le jardin et la formule UTILE-DULCIS ; Dans le bas à gauche se trouve un rappel de l'auteur avec ses armoiries, sa mitre, sa crosse d'Abbé éminent ; et à droite, l'équivalent... pour Augustin Erath ! Voici les deux personnages mis sur le même plan et la question se pose de savoir quelle part a pris Erath dans l'édition latine - Question sans réponse.

Cette interrogation n'est pourtant pas anecdotique. Depuis la mise en œuvre du Simbolico par Picinelli, paru en 1653 mais entrepris plusieurs années auparavant, c'est l'univers des jeux en son entier qui a évolué au cours du XVIIe siècle, en Italie et ailleurs. Les jeux d'argent autrefois réservés aux soldats dans les tripots et à l'aristocratie entrent peu à peu dans la bourgeoisie en formation, même si les mises sont modestes ou symboliques. En même temps, si l'on peut dire, les jeux : «entrent en littérature » irriguant d'une façon décisive la société nouvelle. Deux repères français sont intéressants car ils sont quasiment contemporains du Simbolico. Le premier est La maison de jeux de Charles Sorel dont trois éditions se succèdent (1642,

Board Game Studies Journal 11, pp. 1-52 DOI 10.1515/bgs-2017-0001 
1643 et 1657) - où se trouvent les divertissements d'une compagnie...20: le second : La maison des jeux académiques de La Marinière où l'on trouve les règles des jeux « pour se réjouir agréablement dans les bonnes compagnie » (1654). L'Italie connait la même évolution et c'est certainement pour cette raison que Picinelli les considère avec autant d'attention.

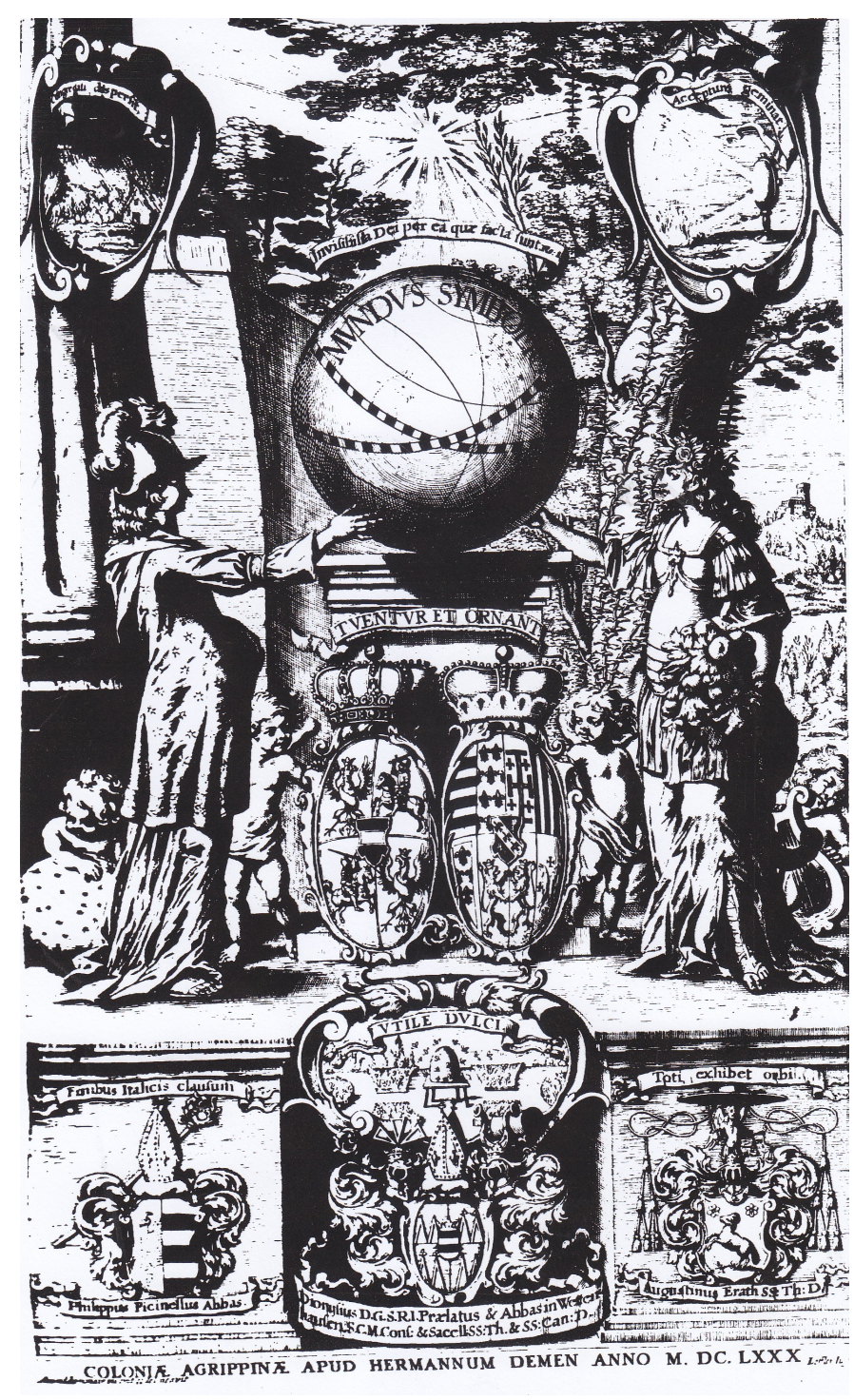

\footnotetext{
Honoré Champion 2017

${ }^{20}$ Le premier tome d'une édition critique par Marcella Leopizzi, vient de paraitre- 


\section{LISTE DES JEUX DANS LES ÉDITIONS ITALIENNES ET LATINES \\ Italien Latin \\ Chap. I DADO ALEA \\ Chap. II FARINACIO ALVEUS LATRUNCULUM \\ Chap. III CIRAVENDO PILA \\ Chap. IV PALLA PILA RETICULO PERCUSSA \\ Chap. V PALLONE BRACCIALE PILA VENTOSA LIGNEUM BRACHII TEGMEN \\ Chap. VI RACHETTA PYROBOLUS CHARTACEUS \\ Chap. VII RAZZO TESSERA \\ Chap. VIII SCACCHIERE TROCHUS \\ Chap. IX TROTTOLA TURBO PNEUMATICUS}

L'édition latine utilisée est celle de 1715-la première trouvée et la première explorée. Des différences infimes avec l'édition 1681 montrent qu'elle n'est pas une réimpression mais dans le Livre XVIII, consacré aux jeux, le texte est exactement le même, ainsi que le nombre des paragraphes : 90 .

Les différences paraissent considérables. Pourquoi changer l'ordre des jeux ? La réponse est toute simple : pour respecter l'ordre alphabétique. Les lecteurs ne peuvent comparer les deux éditions et s'en rendre compte. La disparition des échecs dans les éditions latine est troublante. En fait, il y a malgré tout moins de changements qu'il n'y parait ; en particulier parce que notre Augustin Erath a des difficultés pour proposer des traductions exactes. On pense que le Farinaccio a disparu en regardant la liste, mais on verra que son texte est attribué tel quel au chapitre Tessera. Razzo et ses fusées se retrouvent dans Pyrobolus chartaceus. Plus amusant et surprenant Erath confond la toupie et le cerceau, il traduit en effet Trottola par Trochus. Le chapitre vraiment nouveau, long et difficile, est celui consacré aux latroncules ; chacun peut se référer au texte original s'il le désire.

\section{ALEA}

\section{Chap.I [1-9]}

Le premier chapitre est intitulé Alea. Le mot signifie bien « jouer aux dés », mais insiste sur l'aspect hasardeux du divertissement, sur la chance, sur le risque... .

Aucune surprise de la part de religieux, qu'il s'agisse de Picinelli ou d'Erath, face aux jeux de hasard, suspects par nature à leurs yeux. Le début a été vu plus haut, page 10. Méfiance devant l'accoutumance, prudence, 
apparition inévitable des "nuisibles"... Et lecture au début du paragraphe 6, de l'expression «Damnatos, ceternis cruciatibus exagitando »; la condamnation à des tourments éternels pour les irrécupérables. La notion de péché s'exprime alors clairement dans un monde fallacieux. La conclusion est claire, résumée par saint Augustin : «Pour gagner vous avez offensé Dieu ; la perte est plus grande que le gain. »

\section{ALVEUS LATRUNCULORUM}

\section{Chap.II [10-22]}

La règle précise du jeu des latroncules est mal connue; ce texte éclairera peutêtre un peu les spécialistes. Le titre alveus latrunculum évoque à la fois, les pions et le tablier. «Valeur propre » noté dans la marge donne le ton. « Le concours est pour jouer aux dés, ou par tirage au sort, parmi les autres jeux de calcul ; et le jugement de la table des latroncules est déterminé sur l'unique compétence des joueurs. D'où la table de manière ludique pour répondre à cet adage : PAS LE MOINDRE SORT ; cette forme de programme assure que l'on n'obtient nulle part une nouvelle faveur mais de sa propre valeur et d'une prudence encore plus difficile. » Suit un poème en italien, dans le même esprit, et un nouvel adage : INTELLIGENCE NON SORT.

Le commentaire propose alors une référence à Dieu dans la mesure où le roi réunit tous les pions en donnant du travail à tous [LABOR OMNIBUS UNUS], de même pour les opérations de la puissance de Dieu et Dieu luimême... et l'on trouve invoqué le célèbre verset de Matthieu « Tu aimeras le Seigneur ton Dieu de tout ton cour, de toute ton âme et de tout ton esprit », les mots dans la marge sont Servitus Dei, un mot qui va plus loin que serviteur mais est souvent utilisé pour "esclave". Suit un très long paragraphe sous le signe du Progrès, où se mêlent des considérations sur la marche du jeu et la vie des fidèles.

Les thèmes évoqués ensuite sont les suivants : Ministres fallacieux et vides / La mort est égale pour tous / La victoire est ouverte à tout le monde / mutation / De petites forces sont en danger de l'ennemi / Les espoirs de maturité / Le nom de Jésus / Vierge Marie / Conduite de la science scholastique / Insignifiance de l'homme. 


\section{PILA}

\section{Chap.IIi [23-39]}

Jeu traité dans les éditions italiennes [Palla ch. IV] ; cf. plus haut : p.19 $\& 37$.

\section{PILA RETICULO PERCUSSA}

Chap.IV $[40,41]$

Jeu traité dans les éditions italiennes [Rachetta $\mathbf{c h}$. VI], cf. plus haut p.24.

\section{PILA VENTOSA}

\section{Chap.V [42-52]}

Jeu traité dans les éditions italiennes [Pallone Bracciale ch.V] cf. plus haut p.22, 38 .

\section{LIGNEUM BRACHI TEGMEN}

[53-55]

Jeu traité dans les éditions italiennes [Bracciale] cf. plus haut p.24, 38 .

\section{PYROBOLUS CHARTACEUS}

\section{Chap. VI [56-76]}

Jeu traité dans les éditions italiennes [Razzo, Folgoretto, Sofione ch.VII] cf. plus haut p.25, 36 .

\section{TESSERA}

\section{Chap. VII [77-79]}

Jeu traité dans les éditions italiennes [Farinacio, chap.II] cf. plus haut p.17. 


\section{TROCHUS}

\section{Chap. VIII [80-88]}

Jeu traité dans les éditions italiennes [Trottola, chap. IX] confusion entre toupie et cerceau ; cf. plus haut p.28, 39 .

\section{TURBO PNEUMATICUS}

\section{Chap. IX $[89,90]$}

Jeu traité dans les éditions italiennes [Giravendo, chap. II] cf. plus haut p. 18.

Le chapitre sur les jeux est l'un des plus courts de l'ouvrage. Rappelons que celui-ci comprend deux parties ; la première consacrée au monde créé, dans lequel l'homme se trouve et la seconde partie consacrée aux œuvres des hommes. Les diverses éditions contiennent le même nombre de LIVRES (25) ; chaque Livre est divisé en CHAPITRES (nombre variable) et en PARAGRAPHES (nombres variables). Les deux parties sont sensiblement équivalentes en nombre de thèmes traités : 13 Livres dans la première et 12 dans la seconde.

\section{Titres des Livres de la première partie}

I Corps célestes ; II Corps élémentaires (à partir des quatre Éléments) ; III Les hommes et l'histoire (profane et sacrée) ; IV Les oiseaux ; V Les quadrupèdes ; VI Les poissons ;

VII Serpents et animaux venimeux ; VIII Insectes ; IX Arbres et Fruits ; X Plantes sauvages ;

XI Fleurs ; XII Gemmes et Pierres ; XIII Métaux.

\section{Titres des Livres de la seconde partie :}

XIV Instruments ecclésiastiques ; XV Instruments domestiques ; XVI Édifices ;

XVII Instruments mécaniques ; XVIII Jeux ; XIX Lettres, Alphabet, Livres ; XX Instruments nautiques ; XXI Instruments mathématiques ; XXII Instruments militaires ; XXIII Instruments de musique ; XXIV Instruments agricoles ; XXV Corps et objets composés (exemple : Ruche) 
Le livre sur les corps célestes comporte 14 chapitres et 423 paragraphes ; celui sur les quadrupèdes 50 chapitres et 700 paragraphes. Sur les instruments ecclésiastiques, 12 chapitres et 81 paragraphes ; sur les jeux, 9 chapitres et 90 paragraphes... Le plus long des Livres est celui des hommes et de l'histoire : 102 pages, le plus court celui des lettres, de l'alphabet et des livres : 9 pages... Les index couvrent 231 pages.

La composition du livre sur les jeux est curieuse : Livre 18 - 9 chapitres90 paragraphes. Ce rapport au chiffre 9 existe seulement dans les éditions latines ; il est difficile de penser qu'elle soit fortuite. Ce serait une sorte de jeu de la part d'Augustin Erath car aucune relation de ce genre ne peut être établie avec les autres Livres de l'ouvrage.

Un regret : ne pas voir apparaitre les cartes à jouer parmi les jeux présents. Au début du $17^{\mathrm{e}}$ siècle, étaient-elles assez répandues pour que Picinelli s'en préoccupe ?

Il s'agit d'une Encyclopédie, au plein sens du terme, avec tous les chapitres classés par ordre alphabétique à l'intérieur des vingt-cinq Livres constituant l'ensemble. Ce caractère d'universalité a conféré au Simbolico, comme au Symbolicus, l'audience tout de même importante qui a été observée. L'ouvrage n'apparait pas dans les études consacrées aux encyclopédies traditionnelles ; c'est dommage. Est-ce en raison de son caractère religieux ? La masse d'informations recueillies est considérables ; tout cela à la main, mot par mot. Même si Augustin Erath a pu intervenir, le travail est d'un seul auteur : Filippo Picinelli.

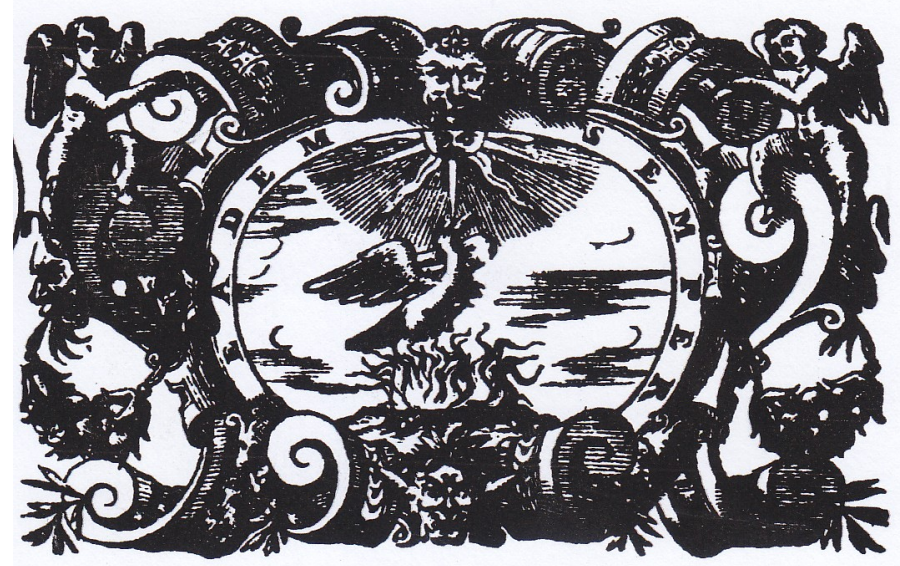

Édition 1653 marque d'imprimeur 